\title{
PHD2 deletion in endothelial or arterial smooth muscle cells reveals vascular cell type-specific responses in pulmonary hypertension and fibrosis
}

\author{
Harri Elamaa ${ }^{1,2} \cdot$ Mika Kaakinen $^{1,2} \cdot$ Marjut Nätynki $^{1,2} \cdot$ Zoltan Szabo $^{2,3} \cdot$ Veli-Pekka Ronkainen $^{2} \cdot$ Ville Äijälä $^{1,2}$. \\ Joni M. Mäki ${ }^{1,2} \cdot$ Risto Kerkelä $^{2,3} \cdot$ Johanna Myllyharju ${ }^{1,2} \cdot$ Lauri Eklund $^{1,2}$ (1)
}

Received: 17 February 2021 / Accepted: 29 November 2021 / Published online: 8 January 2022

(C) The Author(s) 2022

\begin{abstract}
Hypoxia plays an important regulatory role in the vasculature to adjust blood flow to meet metabolic requirements. At the level of gene transcription, the responses are mediated by hypoxia-inducible factor (HIF) the stability of which is controlled by the HIF prolyl 4-hydroxylase-2 (PHD2). In the lungs hypoxia results in vasoconstriction, however, the pathophysiological relevance of PHD2 in the major arterial cell types; endothelial cells (ECs) and arterial smooth muscle cells (aSMCs) in the adult vasculature is incompletely characterized. Here, we investigated PHD2-dependent vascular homeostasis utilizing inducible deletions of PHD2 either in ECs $\left(P h d 2^{\triangle \mathrm{ECi}}\right)$ or in aSMCs $\left(P h d 2^{\triangle \mathrm{aSMC}}\right)$. Cardiovascular function and lung pathologies were studied using echocardiography, Doppler ultrasonography, intraventricular pressure measurement, histological, ultrastructural, and transcriptional methods. Cell intrinsic responses were investigated in hypoxia and in conditions mimicking hypertension-induced hemodynamic stress. $P h d 2^{\Delta \mathrm{ECi}}$ resulted in progressive pulmonary disease characterized by a thickened respiratory basement membrane (BM), alveolar fibrosis, increased pulmonary artery pressure, and adaptive hypertrophy of the right ventricle (RV). A low oxygen environment resulted in alterations in cultured ECs similar to those in $P h d 2^{\Delta \mathrm{ECi}}$ mice, involving BM components and vascular tone regulators favoring the contraction of SMCs. In contrast, $P h d 2^{\triangle \mathrm{aSMC}}$ resulted in elevated RV pressure without alterations in vascular tone regulators. Mechanistically, PHD2 inhibition in aSMCs involved actin polymerization -related tension development via activated cofilin. The results also indicated that hemodynamic stress, rather than PHD2-dependent hypoxia response alone, potentiates structural remodeling of the extracellular matrix in the pulmonary microvasculature and respiratory failure.
\end{abstract}

Keywords Pulmonary hypertension · Fibrosis $\cdot$ Basement membrane $\cdot$ Endothelial cell $\cdot$ Smooth muscle cell $\cdot$ Extracellular matrix $\cdot$ Hypoxia

Harri Elamaa and Mika Kaakinen contributed equally to this work.

Lauri Eklund

lauri.eklund@oulu.fi

1 Oulu Centre for Cell-Matrix Research, Faculty of Biochemistry and Molecular Medicine, University of Oulu, Oulu, Finland

2 Biocenter Oulu, University of Oulu, Oulu, Finland

3 Medical Research Center Oulu, Research Unit of Biomedicine, University of Oulu and University Hospital Oulu, Oulu, Finland

\section{Introduction}

In the vasculature oxygen-sensing systems provide an important mechanism to induce angiogenic growth and to adjust blood flow via arterial vasodilatation and constriction. The mechanism involves the transcription factor HIF [1], the stability of which is mainly controlled by prolyl 4-hydroxylase-2 also named as EGNL1 or PHD2. The importance of PHD2-dependent intrinsic responses in two major arterial cell types, endothelial (ECs) and arterial smooth muscle cells (aSMCs), in chronic vascular pathologies in adults are incompletely characterized.

A loss-of-function $P h d 2$ allele in the germline resulted in embryonic lethality between embryonic (E) days E12.5 and E14.5 due to dysmorphogenesis of the placental labyrinth 
layer that was associated with poorly vascularized placenta and incomplete cardiac development [2]. As the cardiac phenotype could possibly develop secondary to the placental defect the exact role of PHD2 in vascular development is not completely understood in mice. Nevertheless, in Xenopus leavis embryo development, which is not placenta dependent, suppression of $P h d 2$ led to decreased formation of embryonic blood vessels [3]. Interestingly, in postnatal mice inducible global deletion of the floxed $P h d 2$ allele using the ubiquitously expressed Rosa26 $6^{\text {CreERT2 }}$ deleter mouse line at six weeks of age resulted in excessive angiogenesis and dilation of blood vessels [4], severe polycythemia causing venous congestion, dilated cardiomyopathy and increased mortality [5]. Collectively these previous studies indicated that PHD2 activity is needed for both developmental angiogenesis and in vascular homeostasis after birth and that PHD2 has differential roles in embryonic and in adult cardiovascular system.

The importance of PHD2 in ECs has been addressed by crossing the floxed $P h d 2$ allele with Tie2-Cre [6] and VECadherin-Cre transgenes [6-8]. Phd2 deletion by these Cre drivers resulted in obliterative arterial remodeling in the lungs [6-8] and kidneys [7] as well as pulmonary arterial hypertension (PAH) and renal fibrosis when analyzed in adulthood. In Tie 2 and VE-Cadherin promoter driven mice Cre is expressed form early development starting at E7.5 in blood and lymphatic ECs $[9,10]$. The promoters are not exclusively expressed in ECs, but also in hematopoietic cells, some circulating cells, fibroblasts and in the mesenchymal cells of the atrioventricular canal and in part of the proximal cardiac outflow tract [9-11]. As cardiac perivascular cells can develop from ECs after E7.5 [12] Tie2-Cre and $V E$-Cadherin-Cre can also result in $P h d 2$ deletion in a wider manner including pericytes and in vascular SMCs. Understanding the importance of PHD2 arterial smooth muscle cells (aSMCs), which are the key cell type in the regulation of pulmonary arterial pressure, is of particular interest due to link between PHD2 deficiency and PAH. In a previous study PHD2 [13] was deleted using inducible generic SMC deleter Smmhc-CreER ${ }^{\mathrm{T} 2}$ mouse line [14] that enhanced pulmonary and cardiovascular pathologies in hypoxia and in hypertensive mice, but not in normoxia. From a translational point of view, deletion of PHD2 in aSMCs would be especially informative to better understand the pathophysiology of PAH, however, the current limitation is that there is no selective Cre driver line for conditional gene modifications in aSMCs [15]. In addition, due to differential effects of PHD2 deletion in embryonic angiogenesis and adult vasculature, the current models are inadequate to investigate the importance of endothelial PHD2 in vascular homeostasis in quiescent endothelium. To overcome these limitations, we generated $P h d 2^{\Delta \mathrm{ECi}}$ mice to address the importance of PHD2 in ECs after embryonic development. In addition, to investigate PHD2 deficiency in pulmonary aSMCs, we generated $P h d 2^{\triangle \mathrm{aSMC}}$ mice using a novel deleter mouse line (Angpt $4^{\mathrm{Cre}}$ ) that in the lungs drives Cre expression in aSMCs starting in postnatal mice.

The PHD/HIF signaling pathway is involved in a large number of developmental processes, in adult homeostasis and pathologies having either protective or deleterious effects [16-19], and it has also emerged as an important target for drug development [20]. Clearly, in depth investigation of the cell type-specific roles of PHD2 in complex systems is biologically interesting and clinically highly relevant. In our study, longitudinal investigation of $P h d 2^{\Delta \mathrm{ECi}}$ revealed progressive lung disease characterized by increased pulmonary artery pressure, interstitial fibrosis, and compensatory RV hypertrophy. Surprisingly, and in contrast to previous models where PHD2 was deleted from ECs starting from embryogenesis, $P h d 2^{\Delta \mathrm{ECi}}$ resulted in an increased pulmonary artery pressure gradient and cardiac hypertrophy without structural remodeling of the pulmonary arteries (i.e. no alterations in aSMC proliferation, arterial wall or periarterial extracellular matrix). Our study is also the first to show that long-term PHD2 deletion in ECs results in alveolar capillary basement membrane (BM) thickening and increased basement membrane (BM) collagen IV expression that may impair gas exchange and thus aggravate symptoms in PAH. Analysis of $P h d 2^{\triangle \mathrm{aSMC}}$ mice, for the first time, revealed the PHD2-dependent hypoxia response in pulmonary arterial SMCs in vivo indicating novel, autonomous role for PHD2 in aSMCs in maintaining vascular tone. Mechanistically, PHD2 inhibition in aSMCs was associated with cofilin dephosphorylation which has been shown to enhance actin polymerization and related tension development [21]. Finally, we dissected the contribution of PHD2-dependent HIF signaling from the mechanical stimulus emerging from elevated blood pressure.

\section{Results}

\section{Generation of inducible postnatal deletion of Phd2 in endothelial cells (Phd ${ }^{\Delta \mathrm{EC}}$ )}

To generate an inducible deletion of $P h d 2$ in ECs, a floxed $P h d 2$ allele was crossed with a $C h d 5^{\text {CreERT2 }}$ driver line [22], which generates complete recombination of the floxed allele in various blood vascular beds including retina, liver, heart, lung, kidney and brain. Tamoxifen was administered as detailed in the Material and Methods starting at one month of age and the mice were studied at 3,6 , and 10 months of age. The efficacy of EC-specific recombination between loxP sites was confirmed in the Chd5 ${ }^{\mathrm{CreERT} 2}$; Rosa $26^{\mathrm{mT} / \mathrm{mG}}$ reporter line as described previously [23]. Based on analysis of the retinal flat mounts, 
lung and heart tissue sections, Cre/loxP recombination was complete in $C h d 5^{\text {CreERT2}}$; Rosa $26^{\mathrm{mT} / \mathrm{mG}} \mathrm{ECs}$ and did not occur in other cell types (Fig. 1A). Based on PCR analysis of the genomic sequence over the floxed region (Fig. 1B), deletion of the $P h d 2^{\text {flox }}$ allele occurred in tamoxifen-treated $C h d 5^{\mathrm{CreERT} 2} ; P h d 2^{\text {flox }}$ mice resulting in a reduction in PHD2 expression in the lungs as expected (Fig. 1C). Keeping in mind that about $30 \%$ of all lung cells are ECs [24], a 26.1\% reduction in PHD2 protein in the total lung preparation from tamoxifen-treated $C h d 5^{\text {CreERT2; }}$ $P h d 2^{\text {flox/flox }}$ mice $\left(P h d 2^{\Delta \mathrm{ECi}}\right.$ onwards) indicated almost complete deletion of $P h d 2$ in ECs resulting in stabilization of HIFs (Fig. 1D and E, Supplemental Figs. 1, 2). Comparison of $P h d 2^{\Delta \mathrm{ECi}}$ with previously reported noninducible transgenic Chd5-Cre mice $[8,25]$ indicated similar deletion efficacies.

\section{Phd2 ${ }^{\mathrm{DECi}}$ mice develop increased pulmonary artery and right ventricular pressure, right ventricular hypertrophy and increased cardiac contractile function}

As $P h d 2^{\Delta \mathrm{ECi}}$ showed no readily apparent phenotype at 3 or 6 months of age, we first investigated possible indications in more detail in the oldest (10-month-old) $P h d 2^{\Delta \mathrm{ECi}}$ cohort. In contrast to the inducible global deletion of floxed $P h d 2$ allele [5] in $P h d 2^{\Delta \mathrm{ECi}}$ we observed no erythema, hemorrhages, venous congestion, nor premature mortality. Nevertheless, gravimetric analysis revealed cardiac hypertrophy (Fig. 2A, B) as previously found in mice where PHD2 was deleted in ECs starting in early embryonic development [6-8]. As RV hypertrophy is a commonly used diagnostic measure of PAH [26], we next measured RV dimensions in living
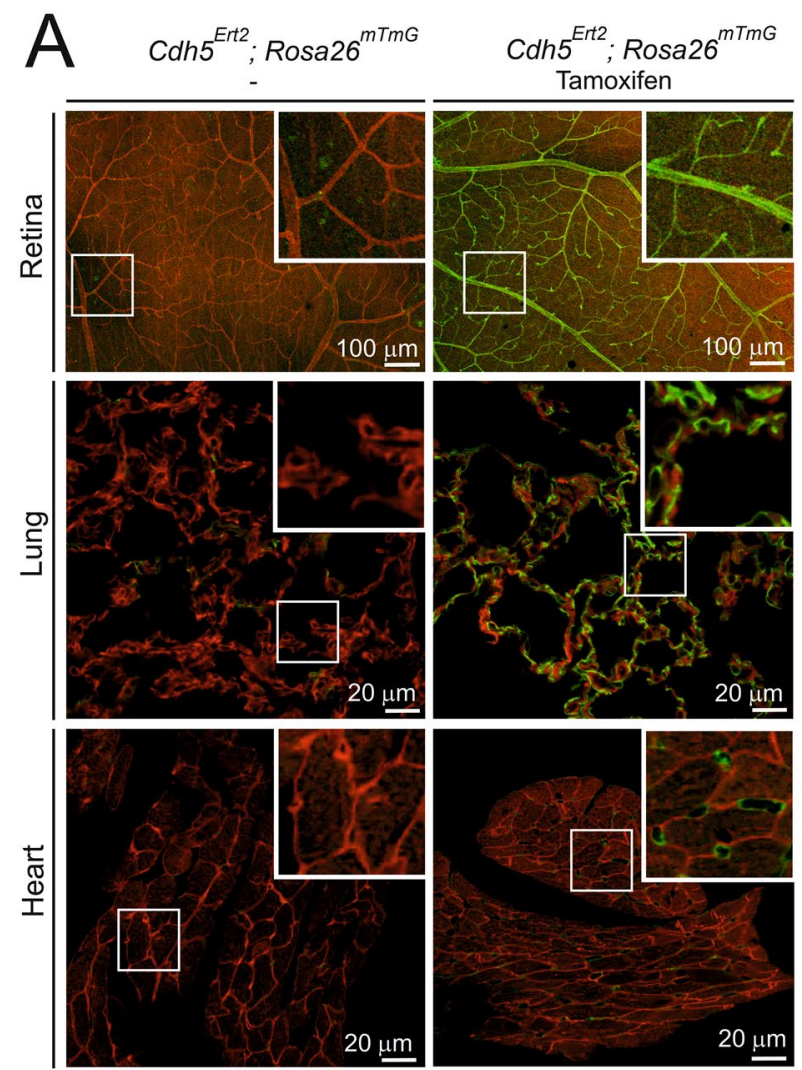
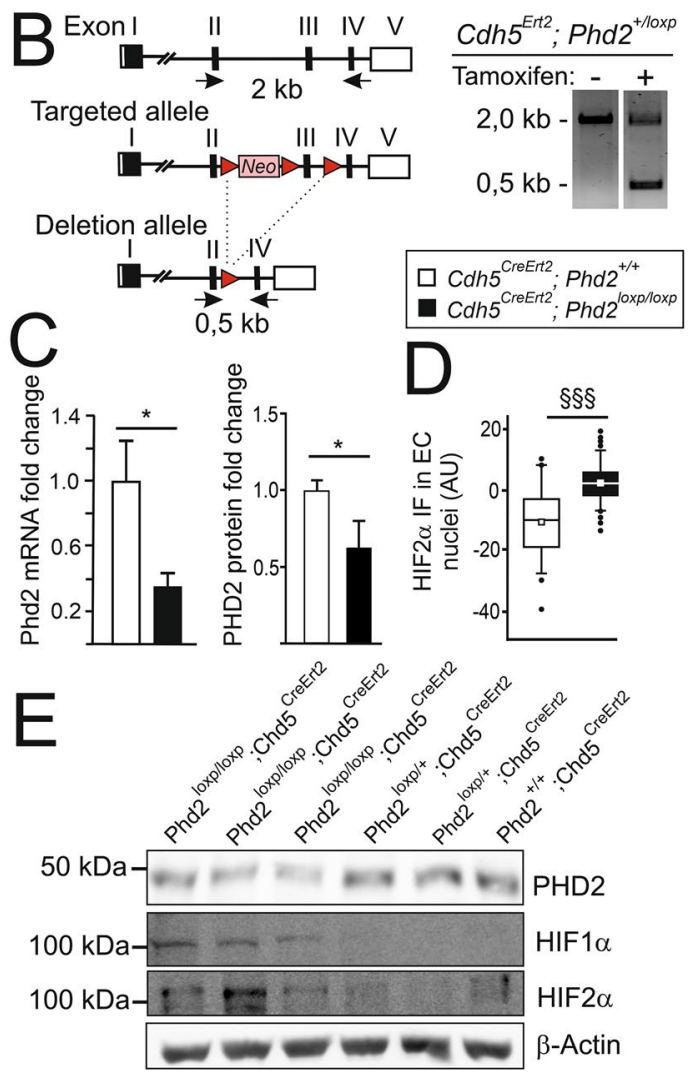

Fig. 1 Endothelial cell-specific Cre/loxP recombination and PHD2 deletion in $P h d 2^{\Delta \mathrm{ECi}}$ mice. A The tissue samples collected from 10-month-old mice and imaged with the confocal microscope. In $C d h 5^{\text {CreErt2 }}$ Rosa $26^{\mathrm{mT} / \mathrm{mG}}$ mice, mTomato (red) is ubiquitously expressed until the tamoxifen-induced Cre/loxP recombination that induces GFP (green) expression. Tamoxifen-treated mice (right) show GFP-signal in ECs, whereas in the untreated control (left) only weak and non-EC background is detected. B WT (up), targeted Phd2 locus (middle) and Cre-loxP mediated deletion of exon 3 encoding the catalytic domain of PHD2 (bottom). Red triangles, loxP sites; arrows, location of PCR primers to detect WT and deletion alleles. In tamoxifen-treated $C d h 5^{\mathrm{CreErt} 2}$; $\mathrm{Phd} 2^{+/ \text {loxP }}$ mice genomic PCR (right) indicates $P h d 2$ deletion ( $0.5 \mathrm{~kb}$ PCR product). C mRNA and protein levels quantified by qPCR and Western blot (E). D Relative HIF $2 \alpha$ immunofluorescence intensity in arterial EC nuclei, $n=56$ and 122 nuclei from two control and four tamoxifen-treated $C d h 5^{\mathrm{CreErt} 2}$; $P h d 2^{\text {loxP/loxP }}$ mice. Median (line), average (square), 75th quartile (box), 5th and 95th percentile (whiskers), outliers (•). E Western blot analysis of 3-month-old mouse lung lysates showed diminished PHD2 protein level and stabilization of HIF1 $\alpha$ and HIF2 $\alpha$ in tamoxifen-treated $C d h 5^{\text {CreErt2 }} ; P h d 2^{\text {loxP/loxP }}$ mice. Note that both mRNA and protein analysis $(\mathbf{C}, \mathbf{E})$ detect residual non-endothelial PHD2 as expected. Mean \pm SD. ${ }^{*} P<0.05$ in $t$-test, ${ }^{\$ \S \S} P<0.001$ in Mann-Whitney test 
Fig. 2 Cardiac hypertrophy, elevated pulmonary arterial and right ventricular pressures in $P h d 2^{\Delta \mathrm{ECi}}$ mice. A Representative images of 10-month-old mice hearts (top) indicating increased cardiac size in $P h d 2^{\Delta \mathrm{ECi}}$. Masson trichrome staining of transverse histological sections (bottom) show increased thickness of right ventricular (RV) wall (asterisk) without evidence of fibrosis or ventricle dilation. $\mathrm{LV}$, left ventricle. B Increased heart weight to body weight ratio in 3 to 10 month-old $P h d 2^{\Delta \mathrm{ECi}}$ mice, $n=8-19$ mice/group. C, RV wall thickness measured by M-mode in echocardiography at 3 months of age. D Pulmonary artery (PA) pressure calculated from Doppler ultrasound data. E RV developed pressure. $\mathbf{F}$ Rate of RV pressure development. G qPCR analysis of endothelial PAH marker genes in mouse lungs, $n=5-8$ mice/ group. $\mathbf{H}$ qPCR analysis of endothelial PAH marker genes in ECs cultured in normoxic or hypoxic conditions for 7 days. C-F, 6-10 mice/group; $\mathbf{H}$ the experiments were repeated 3 to 4 times. Mean \pm SD. $* P<0.05$, $* * P<0.01$ and $* * * P<0.001$ in $t$-test. Mo, month
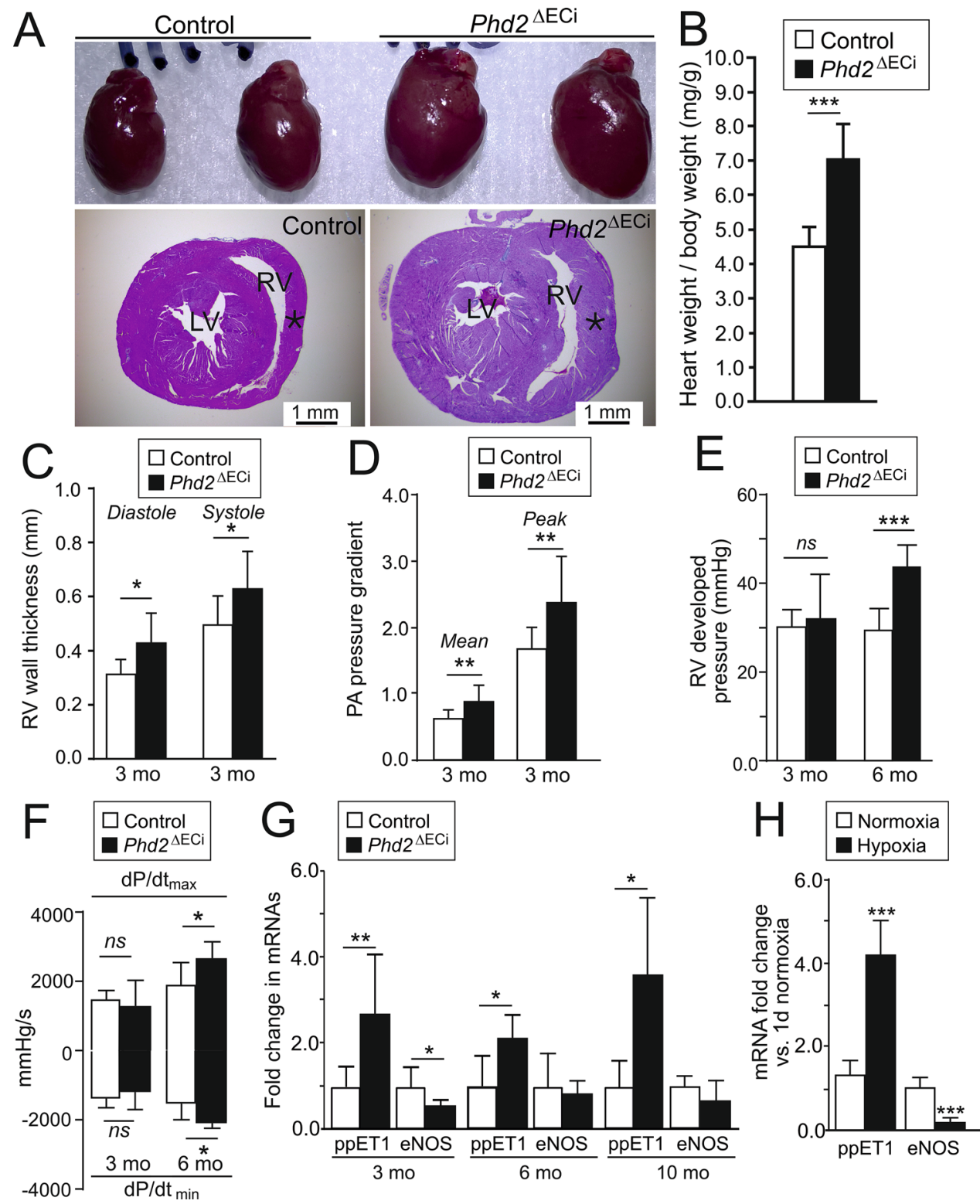

mice using transthoracic echocardiography. This indicated increased $\mathrm{RV}$ wall thickness in $P h d 2^{\Delta \mathrm{ECi}}$ mice at 3 months of age (Fig. 2C). In PAH RV hypertrophy develops as a compensatory response to chronic pressure overload that was investigated using Doppler velocimetry (indicating flow velocity in the pulmonary artery) [27] and directly from the RV. In Doppler, an indication for increased pulmonary artery pressure was observed at 3 months of age (Fig. 2D). Intraventricular catherization measurements showed that at 3 months age RV pressure was increased in some, but not all $P h d 2^{\Delta \mathrm{ECi}}$ mice, and there was a significant correlation between the highest and lowest pressure readings and RV wall diameter in systole (Pearson $r=0.84, P=0.018, n=7$ XY pairs). 6-month-old $P h d 2^{\Delta \mathrm{ECi}}$ mice demonstrated a significant increase in RV pressure $(43.94 \pm 4.70 \mathrm{mmHg}$ vs.
$29.87 \pm 4.39 \mathrm{mmHg}$ in controls, $n=6-10$ mice/genotype) as well as enhanced inotropic and lusitropic function (Fig. 2EF), the latter suggesting compensatory rather that pathological cardiac remodeling.

\section{Upregulation of pulmonary arterial hypertension marker genes in the lungs of $P h d 2^{\Delta \mathrm{ECi}}$ mice}

As increased RV and pulmonary arterial pressure are typical indications of PAH [28] we next measured transcript levels of genes previously implicated in this condition (Fig. 2G). Endothelial nitric oxide synthase (eNOS, a vasodilator via NO), was downregulated in 3-month-old $P h d 2^{\Delta \mathrm{ECi}}$ lungs, but not in the older age groups, whereas endothelin I (ppET1, a vasoconstricting factor) was upregulated in all three age 
groups. In ECs cultured in a hypoxic environment $\left(1 \% \mathrm{O}_{2}\right)$ for 7 days, ppET1 was upregulated and eNOS downregulated indicating an EC intrinsic PHD2-dependent hypoxic response (Fig. 2H).

\section{Age-related thickening of respiratory membrane

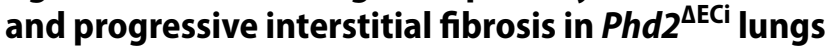 without arterial remodeling}

Current dogma is that PAH occurs as a consequence of obliterative pulmonary vascular remodeling involving aSMC proliferation, tunica media thickening and periarterial fibrosis increasing vascular resistance [28]. In addition, arterial remodeling is a common finding in PAH caused by chronic hypoxia $[8,29,30]$. To confirm the presence of arterial remodeling also in $P h d 2^{\Delta \mathrm{ECi}}$ mice, we carefully investigated the histology and ultrastructure of pulmonary arteries and peripheral arterioles. To our surprise we observed no changes in the number of muscularized arteries or in arterial $\alpha \mathrm{SMA}$ staining in $P h d 2^{\Delta \mathrm{ECi}}$ mice (Fig. 3A-C). Furthermore, based on Ki-67 staining aSMC proliferation rate was similarly low in $P h d 2^{\Delta \mathrm{ECi}}$ (3 positive nuclei out of $493 \mathrm{aSMCs}$, $n=5$ mice) and in control mice ( 1 positive nucleus out of 385 aSMCs, $n=4$ mice) (Fig. 3D-G). Ultrastructural analyses of pulmonary arterioles with lumen diameters $<40 \mu \mathrm{m}$ (measured from narrowest point) revealed no significant
Fig. 3 Lack of arterial smooth muscle proliferation, arterial wall and perivascular matrix remodeling in $P h d 2^{\Delta \mathrm{ECi}}$ pulmonary arteries/arterioles. $\mathbf{A}$ and $\mathbf{B}$ Lung sections of 10-month-old mice immunostained with alpha smooth muscle actin ( $\alpha$ SMA). Arrows point to $\alpha$ SMA positive arterioles; bronchus (Br). C Area of $\alpha$ SMA positive cells around arteries and arterioles, $n=5$ mice/group, 10 arteries/mouse calculated. D-G, Arterioles (a) stained with Ki-67, $\alpha$ SMA and DAPI. EC and aSMCs nuclei are indicated by arrowheads and arrows, respectively. There was no change in proliferation marker Ki-67 between the genotypes. $\mathbf{H}$ and I Representative TEM micrographs of pulmonary arterioles, thickness of single aSMC is indicated by arrowheads. $\mathbf{J}$ Number of aSMCs/perimeter of arteriole. K Thickness of arterial layers in 10-month-old mice. $n=5-7$ mouse/group (1-4 arteries/mouse). L Expression of SMCs signaling molecules Cxcl12 and Notch3 in the lungs. $n=5-8 \mathrm{mice} /$ group. Mean $\pm \mathrm{SD}$. $* P<0.05, * * P<0.01$ in $t$-test. Mo, month
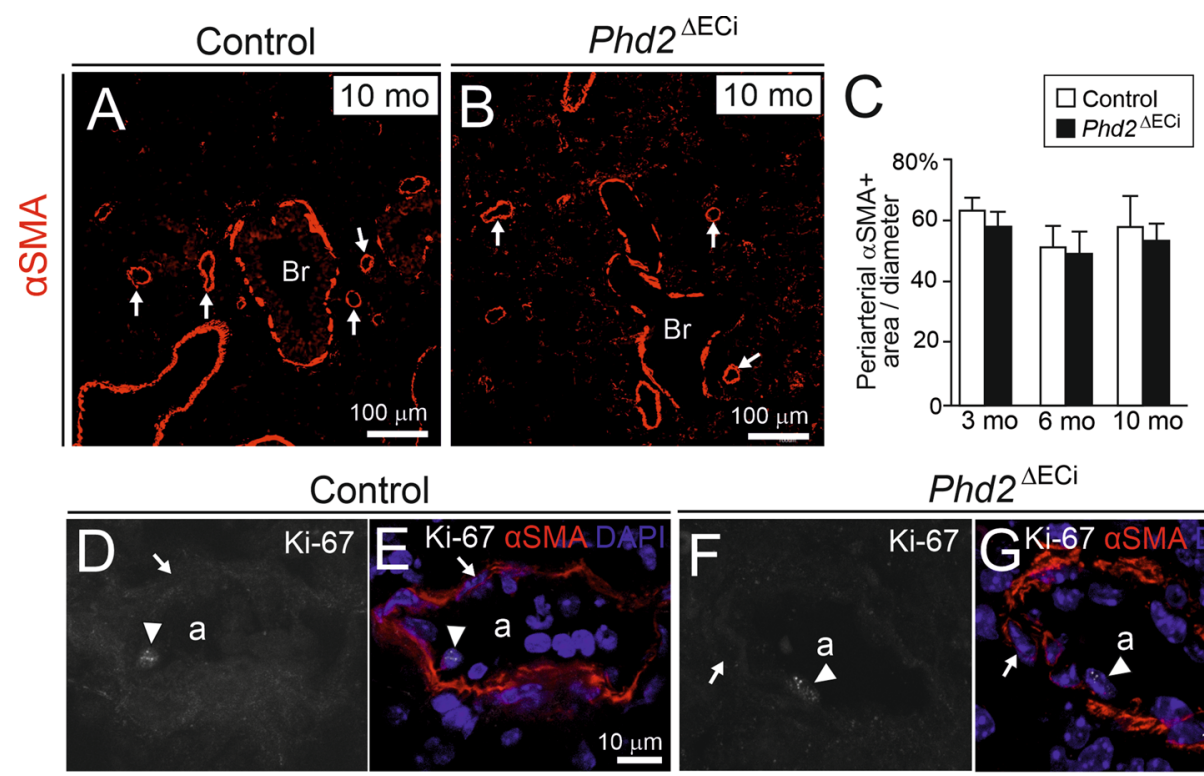

Phd2 $^{\Delta \mathrm{ECi}}$

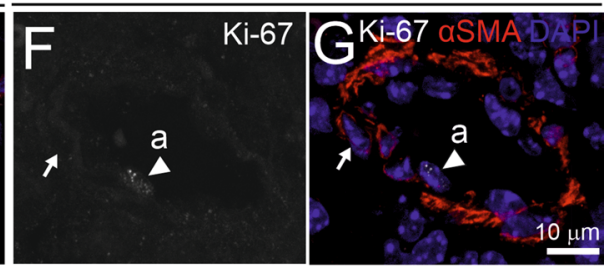

Control
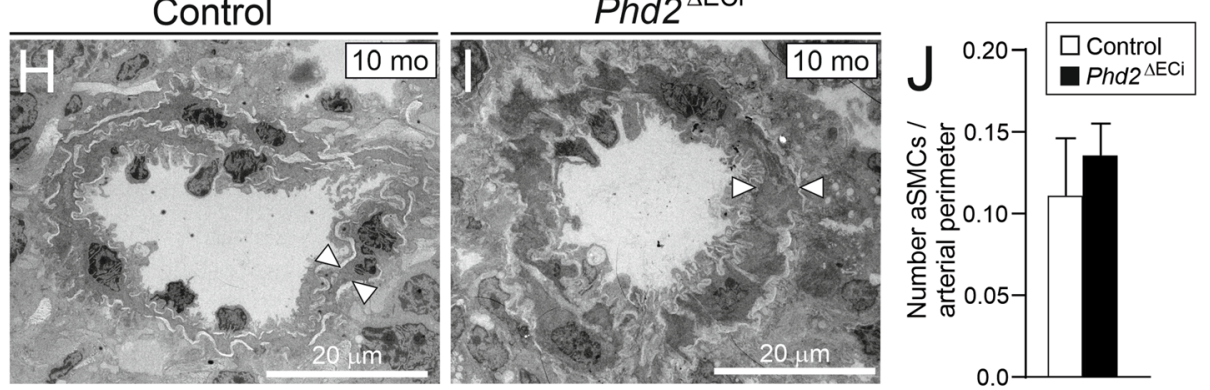
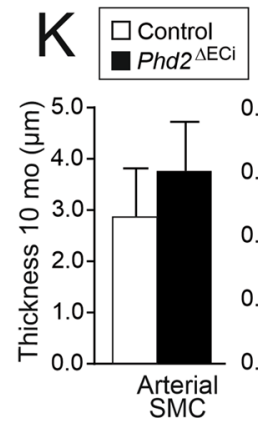

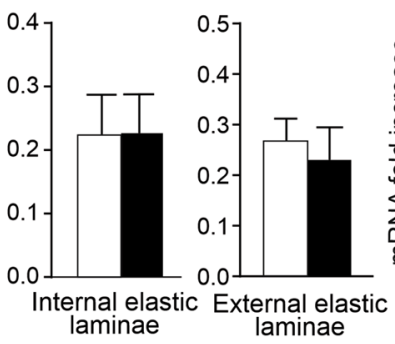

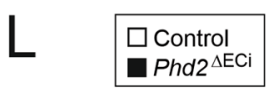

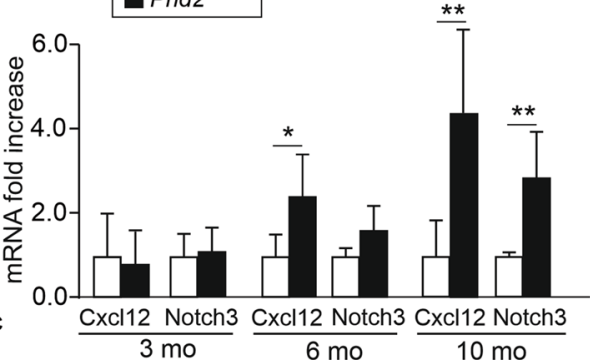


changes in medial wall thickness $(P=0.140, n=5-7$ mice/ group $)$ or in the number of aSMCs $(P=0.176, n=5-6$ mice/ group) in 10-month-old mice (Fig. 3H-K) or in internal and external laminae (Fig. 3K), the thickness of which was previously shown to increase in hypoxic conditions [31]. Previous studies using developmental deletion of $P h d 2$ in ECs (E7.5 onwards) proposed a model where increased Cxcl12 [6] and Notch3 [25] promote pulmonary aSMC proliferation. After 10-month deletion both pathways were upregulated in $P h d 2^{\triangle \mathrm{ECi}}$ lungs (Fig. 3L), indicating that the same SMC stimulating pathways were activated, however, increased expression of these genes was not sufficient for aSMC proliferation in $P h d 2^{\Delta \mathrm{ECi}}$ mice.

Masson trichrome staining, pulmonary weight, and the key transcripts relevant to pulmonary fibrosis (fibronectin, FN; collagen I, Col I) were increased after 10 month Phd2 deletion time indicating progressive pulmonary pathology (Fig. 4A-C). In 10-month-old Phd $2^{\Delta \mathrm{ECi}}$ several fibrotic foci were evident showing interstitial $\alpha$ SMA immunofluorescence, clusters of activated fibroblasts/myofibroblasts and increased fibrillar collagen deposition in the alveolar septum but not around arteries (Fig. 4D-F). To investigate direct involvement of ECs in the fibrotic response due to hypoxia, ECs were exposed to a low oxygen atmosphere that increased FN but not Col I mRNA expression (Fig. 4G). As an additional indication of lung injuries in 10-monthold $P h d 2^{\Delta \mathrm{ECi}}$ mice, we found an increased number of type II pneumocytes [32] $(3.29 \pm 1.15$ vs. $1.66 \pm 0.34$ in control, $P=0.016$ in Welch's $t$-test, $n=5-6$ mice/group) (Fig. 4H) and thickened capillary BMs (Fig. 5A). The latter paralleled the upregulation of Col IV mRNA expression (Fig. 5B), the major component of vascular BMs that was also induced in ECs exposed to low oxygen (Fig. 5C). Increased mechanical stress in alveolar capillaries stemming from elevated blood pressure has been implicated in BM remodeling in $\mathrm{PH}$ [33]. To isolate the impact of mechanical stress from PHD2 dependent hypoxic insult, ECs were subjected to pulsatile mechanical stretching mimicking hypertension-induced hemodynamic load. Interestingly, this resulted in upregulation of Col IV and FN in normoxia (Fig. 5D). Col I was not increased in ECs in hypoxia or in stretching. This suggested EC to stromal cell signaling in the fibrotic lungs to stimulate fibrillar collagen synthesis in cell types other than ECs that typically produce BM constituents.

\section{Right ventricular systolic pressure increases in aged Phd ${ }^{\mathrm{DaSMC}}$ mice independently from endothelial vascular tone marker genes}

The data above suggested that ECs may function as hypoxia sensing cells and that the development of arterial remodeling and lung fibrosis involves other cell types than only ECs. To study the role of PHD2 in aSMCs in vivo we utilized a novel
Angpt $4^{\text {Cre }}$ knock-in allele. In our previous work we found Angpt4 expression in aSMCs of the small intestine mesentery in adult mice [34]. To characterize the spatiotemporal expression pattern of Angpt 4 in more detail, Angpt 4 mRNA expression was investigated by qPCR and its cellular source analyzed in the fate mapping Angpt $4^{\mathrm{Cre}} ; \operatorname{Rosa}_{2} 6^{\mathrm{mT} / \mathrm{mG}}$ mice. In qPCR analysis, the earliest Angpt 4 expression in the lungs was detected at P9. In Angpt $4^{\mathrm{Cre}} ;$ Rosa $26^{\mathrm{mT} / \mathrm{mG}}$ mice Angpt$4^{\mathrm{Cre}}$ expressing cells were observed at P11 around arteries, but not at the earlier time points analyzed (P1 and P4). In Angpt $4^{\mathrm{Cre}} ;$ Rosa $26^{\mathrm{mT} / \mathrm{mG}}$ mice, GFP expression was located in the aSMCs in the medium-sized distributing pulmonary arteries and in arterioles ranging in diameter from approximately $20 \mu \mathrm{m}$ to $100 \mu \mathrm{m}$ (Fig. 6A-D). In addition, GFP was detected in some sparse, fibroblast-like cells (Supplemental Fig. 3). Importantly, and in contrast to commonly used SMC Cre diver lines [15], Angpt $4^{\mathrm{Cre}}$ was not expressed in visceral or bronchial SMCs, and Cre expression did not leak into skeletal or cardiac muscle cells (Fig. 6E, F). This data identified Angpt $4^{\mathrm{Cre}}$ as a potential Cre driver for pulmonary aSMCs and was consistent with the Tabula Muris single cell transcriptome data base, indicating Angpt4 expression in the generic "stromal cell" population in the lungs at three months of age, but not in pulmonary ECs or epithelial cells [35].

$P h d 2^{\text {loxP }}$ was crossed with the Angpt $4^{\text {Cre }}$ allele to generate Angpt $4^{\mathrm{Cre} /+} ; P h d 2^{\text {loxP/loxP }}$ mice (thereafter $P h d 2^{\triangle \mathrm{aSMC}}$ ). Analysis of lung samples from 8-month-old $P h d 2^{\triangle \mathrm{aSMC}}$ mice indicated reduced PHD2 protein level and increased HIF2 $\alpha$ immunofluorescence intensity in aSMC nucleus ensuring Phd2 deletion (Fig. 7A-B, Supplemental Fig. 2). Interestingly, $P h d 2^{\triangle \mathrm{aSMC}}$ mice showed increased RV pressure (Fig. 7C) and relaxation time, but no pulmonary arterial remodeling or other histopathological changes (Fig. 7D-F). Furthermore, and in contrast to $P h d 2^{\Delta \mathrm{ECi}}, P h d 2^{\triangle \mathrm{aSMC}}$ showed no significant change in endothelial vascular tone marker genes ppET1 and eNOS or SMC stimulating factors Cxcl12 [6] and Notch3 [25] (data not shown).

\section{PHD inhibition in cultured arterial smooth muscle cells results in altered actin dynamics}

Increased RV pressure in $P h d 2^{\triangle \mathrm{aSMC}}$ suggested increased aSMC contractility that is primarily regulated by myosin light chain (MLC) phosphorylation and actin polymerization [36]. To investigate the underlying mechanism, we inhibited PHDs using dimethyloxalylglycine (DMOG) [37] in aSMCs. DMOG stabilized HIF but did not increase MLC or MYPT phosphorylation (Fig. 7G). In addition to pMLC driven crossbridge cycling, actin filament assembly, stimulated by non-phosphorylated cofilin enhances SMC contraction [21, 38]. Interestingly, in the DMOG-treated aSMCs the relative 
Fig. 4 Lung fibrosis in aged $P h d 2^{\Delta \mathrm{ECi}}$ mice. A Masson trichrome staining of lung sections show fibrotic foci (blue) in 10-month-old $P h d 2^{\Delta \mathrm{ECi}}$ mice. Lower magnification images in the insets indicate area of detail analysis. B The lung weight to body weight ratio (\%) ((lung weight/body weight $) \times 100$ ), $n=8-19$ mice/group. C qPCR analysis of lung fibrosis marker genes fibronectin (FN) and type I collagen ( $\mathrm{Col} \mathrm{I}), n=5-8$ mice/ group. D Increased number of $\alpha$ SMA positive cells in 10-month-old $P h d 2^{\Delta \mathrm{ECi}}$ lung tissue. Note that $\alpha$ SMA positive cells are evenly distributed and not preferentially located near arteries (image data quantified in $\mathbf{F}$ ). E Ultrastructure of fibrotic area in 10-month-old $P h d 2^{\Delta \mathrm{ECi}}$ shows loss of alveolic structure, increased fibrillar collagen matrix (asterisks) and numerous myofibroblastic cells (arrow heads) as identified based on myofilament rich cytoplasm, presence of dense plaques and lack of BM. F quantification of non-arterial $\alpha$ SMA staining in 10-montholdmice lungs, $n=4-5$ mice/ group. G qPCR of fibrosis marker genes in ECs cultured in hypoxia for 7 days in comparison to normoxia, $n=3$ experiments. H Quantification of type II pneumocytes in $P h d 2^{\Delta \mathrm{ECi}}$ lungs as identified in TEM sections based on surfactant granules, cell size and location $(n=5-6$ mice $)$. Mean \pm SD. $* P<0.05, * * P<0.01, * * *$ $P<0.001$ in $t$-test. Mo, month
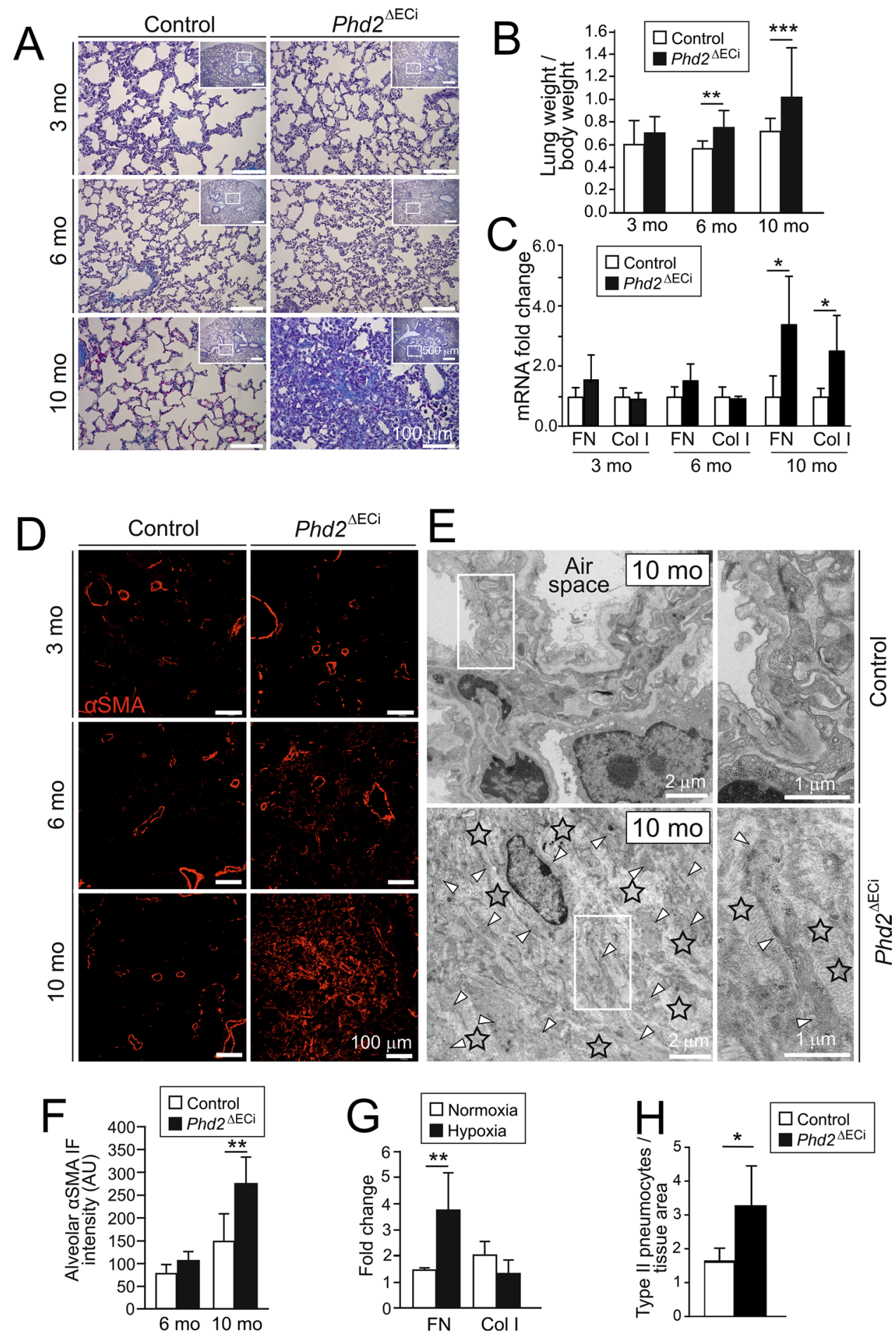

level of non-phosphorylated cofilin was clearly increased (Fig. 7G).

\section{Discussion}

PAH is one form of pulmonary hypertension characterized by sustained pulmonary arterial vasoconstriction and pathological arterial wall remodeling. The primary cause remains elusive in most cases and there is no curative treatment. In the lungs hypoxia results in arterial vasoconstriction to adjust ventilation to perfusion [39]. The PHD2-regulated 

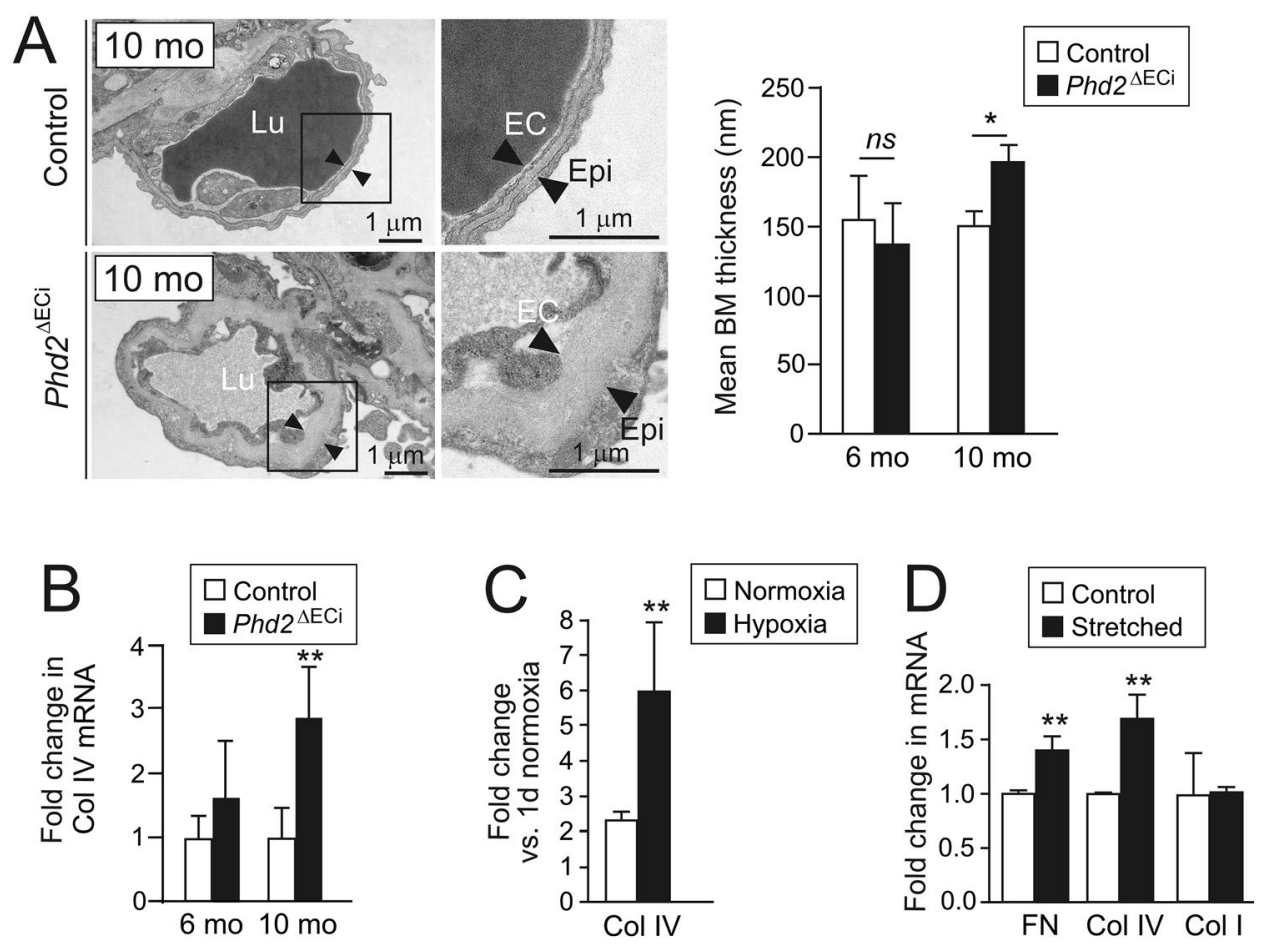

Fig. 5 Phd2 deletion and hypertension mimicking mechanical stretching results in capillary basement membrane thickening. A Respiratory membrane is formed by alveolar epithelial (Epi) and capillary ECs that are separated by alveolar capillary BM (black arrowheads) which main constituent is Col IV. Note thickening of $\mathrm{BM}$ in 10 -month-old $P h d 2^{\Delta \mathrm{ECi}}$ mice. Image data quantified on the right, $n=5-8$ mice/group. B qPCR of Col IV in the lungs, $n=5-8$

HIF hypoxia signaling system has been identified as a potent vasoconstrictive pathway and when chronically activated it results in PAH in genetically modified mice [6-8]. Although still incompletely understood, the outcome of PHD2 inhibition/HIF stabilization likely depends on the timing, extent, and cell type(s) when and where it occurs. This is exemplified in mice carrying a hypomorphic $P h d 2$ allele resulting in lowered $P h d 2$ expression in various cell types (in the lung tissue $35 \%$ to $45 \%$ of WT) and stabilization of HIF $1 \alpha$ and HIF $2 \alpha$, but no alterations in the lung architecture or development of fibrosis [40]. In-depth understanding of the cellular mechanism and signaling pathway by which PHD2 deficiency can result in PAH may help to find molecular targets to alleviate the symptoms in pulmonary diseases. Furthermore, identification of the mechanisms underlying the detrimental effects of PHD2 inhibition is also important from a translational point of view, as PHD inhibitors are in clinical development and the first of them has been recently accepted for the treatment of anemia [20]. Due to shortcomings in previous genetic approaches (the inability to distinguish developmental defects from the pathogenesis occurring in the matured lungs and the lack of desirable cell-type specificity for genetic modifications in ECs and mice/group. C qPCR analysis of Col IV mRNA in ECs cultured in hypoxia for 7 days and compared to normoxia, $n=3$ experiments. D Expression of Col IV, fibronectin (FN), and type I collagen (Col I) mRNAs in vitro model for hypertension induced EC stretching. ECs were exposed to stretching for $24 \mathrm{~h}$ and results were normalized to non-stretched controls, $n=3$ experiments. Mean \pm SD. $* P<0.05$, $* * P<0.01$ in $t$-test. Mo, month

aSMCs), the cellular mechanisms that determine how PHD2 deficiency initiates and promotes pulmonary artery hypertension remains incompletely known. This is particularly true in the case of aSMCs, the key cell type regulating pulmonary vascular tone via vessel dilation/constriction, periarterial matrix production and arterial wall remodeling. In our study, we take advantage of a novel Angpt $4^{\text {Cre }}$ allele that to the best of our knowledge, is the first Cre driver for the generation genetic modifications in the aSMCs. In addition, using inducible, EC-specific gene deletion postnatally $\left(P h d 2^{\Delta \mathrm{ECi}}\right)$ by applying the $C h d 5^{\mathrm{CreERT} 2}$ line $[22,23]$, we were able to separate pathological changes affecting adult vascular homeostasis from the developmental phenotypes occurring in the embryos. Figure 8 summarizes the identified dysregulated signaling pathways and cellular responses in vascular and interstitial cells and their potential contribution to the decreased cardiac and pulmonary function in PAH.

Analyses of the $P h d 2^{\Delta \mathrm{ECi}}$ mice revealed deletion timedependent, progressive changes in the lungs and heart including signs of PAH (increased pulmonary artery and RV pressure, adaptive RV hypertrophy, expression of PAH associated genes) and indicators of increased alveolar wall 

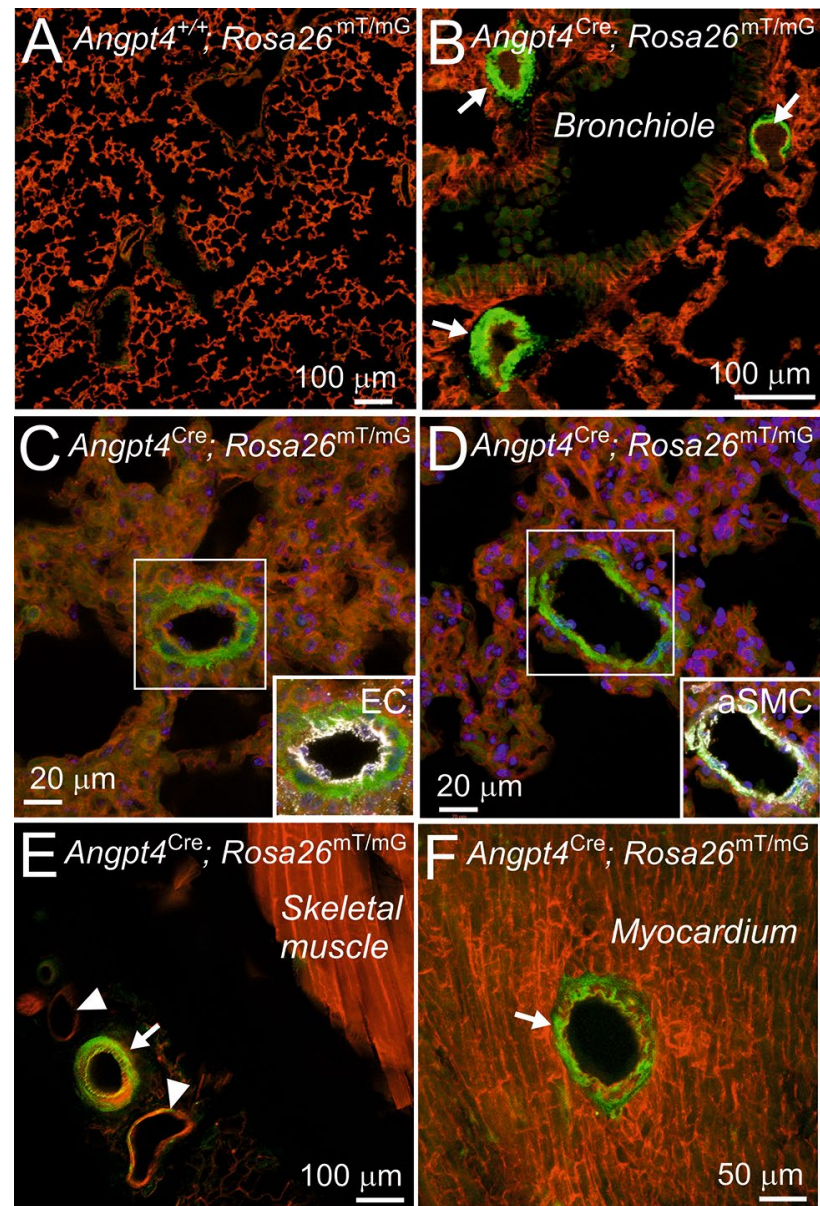

$00 \mu \mathrm{m}$

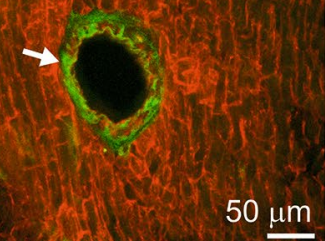

Fig. 6 Arterial smooth muscle cell expression of Angpt $4^{\mathrm{Cre}}$. Angpt$4^{\mathrm{Cre}}$ mice were crossed with Rosa $26^{\mathrm{mT} / \mathrm{mG}}$ cell lineage tracing line that express cell membrane targeted mTomato prior Angpt $4^{\mathrm{Cre}}$-induced

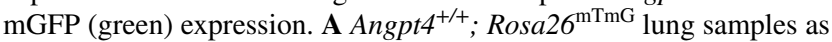
negative control showed ubiquitous mTomato and faint background in

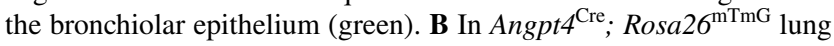
samples GFP is expressed in arterial smooth muscle cells (arrows). C Arterial ECs (pseudo-colored in white) are negative for Angpt $4^{\mathrm{Cr}}$ induced GFP expression. D aSMA staining (white) colocalized with Angpt $4^{\mathrm{Cre}}$-induced GFP in aSMC in arterial media layer. E Femoral aSMCs (arrow) are Angpt $4^{\text {Cre }}$ expressive, veins (arrowheads) are negative or show only some occasional Angpt $4^{\text {Cre }}$ expressing cells. Skeletal muscle is Angpt $4^{\mathrm{Cre}}$ negative. F Arterial media layer (arrow) is positive for Angpt ${ }^{\mathrm{Cre}}$ in the heart, whereas surrounding cardiac muscle is Angpt $4^{\text {Cre }}$ negative. Samples were collected from 6-month-old mice

stress and injury (type II pneumocyte hyperplasia, focal fibrosis, increase in lung weight) [32, 41, 42]. Nevertheless, $P h d 2^{\Delta \mathrm{ECi}}$ did not show arterial wall thickening, aSMC proliferation or apparent occlusion of pulmonary arteries, that are common histopathological findings in PAH. The lack of obliterative arterial remodeling in $P h d 2^{\Delta \mathrm{ECi}}$ model (Cre expression induced at one month of age) was different from non-inducible Tie2-Cre [6] and VE-Cadherin-Cre models
[6-8] in which Cre expression started at early development (at E7.5). We propose that the differences in phenotypes reflect differential roles of PHD2 in embryonic and in adult blood vasculature $[1,2,4]$ and that the extent and time course of the activation of hypoxia signaling also contribute to the severity of vascular disease. This suggestion is in line with the exposure of mice to hypoxia at different ages developing more severe phenotypes when exposed at birth than as mature animals [5, 43, 44].

It is widely accepted that aSMCs have a key role in hypertension, however, due to lack of a specific aSMC Cre-deleter line it has not been possible to investigate the in vivo importance of aSMCs intrinsic responses. Furthermore, at the molecular level, how the activation of the hypoxia signaling pathway results in increased SMCs contractility and proliferation has been controversial. Suggestive for a SMC intrinsic hypoxia response is the observation that HIF $1 \alpha$ protein is increased in cultured pulmonary aSMCs isolated from idiopathic PAH patients [45]. On the other hand, deletion of the floxed Phd2 allele using the smMHC/ Myh11 promoter driven Cre [13] enhanced PAH in hypoxia but not in normoxia, thus suggesting a secondary rather than an initiatory role for aSMCs in PAH pathogenesis. As a potential shortcoming, the smMHC/Myh11 promoter is active in all vascular (arterial, venous) and visceral SMCs and also in lung pericytes [15] that likely influence the phenotype. In contrast to Chen et al. [13] Phd $2^{\Delta \mathrm{aSMC}}$ showed mild hypercontractility (increase in RV pressure) in normoxia but was not associated with lung pathologies as observed in $P h d 2^{\Delta \mathrm{ECi}}$. This indicated that PHD2 deletion in aSMC can increase contractility to elevate RV pressure, but PHD2 deletion in aSMC alone is not sufficient to result in obliterative arterial remodeling, lung damage or fibrosis. Interestingly, in vitro analysis of HIF stabilization in aSMCs suggested that increased contractility may occur via actin polymerization-related tension development via activated cofilin and independently from MLC phosphorylation. The results are in line with a previous report of HIF1 $\alpha$ dependent dephosphorylation of MLC in pulmonary aSMCs [46]. Moreover, there is consistent evidence that actin polymerization plays an essential role in SMC contraction and tension development [47]. One of the main regulators in this context is cofilin, which binds to filamentous actin providing more free barbed ends for actin polymerization [48] and tension development [21]. In aSMCs PHD2 inhibition increased active (dephosphorylated) cofilin thus suggesting that PHD2 deficiency may potentiate vascular pathologies by increasing the contractility of aSMCs and structurally "sensitize" the aSMC cytoskeleton for ET-1 (produced by ECs) induced vasoconstriction [38].

Pulmonary interstitial fibrosis in aged $P h d 2^{\triangle \mathrm{ECi}}$ mice was an additional pathological manifestation of postnatal 

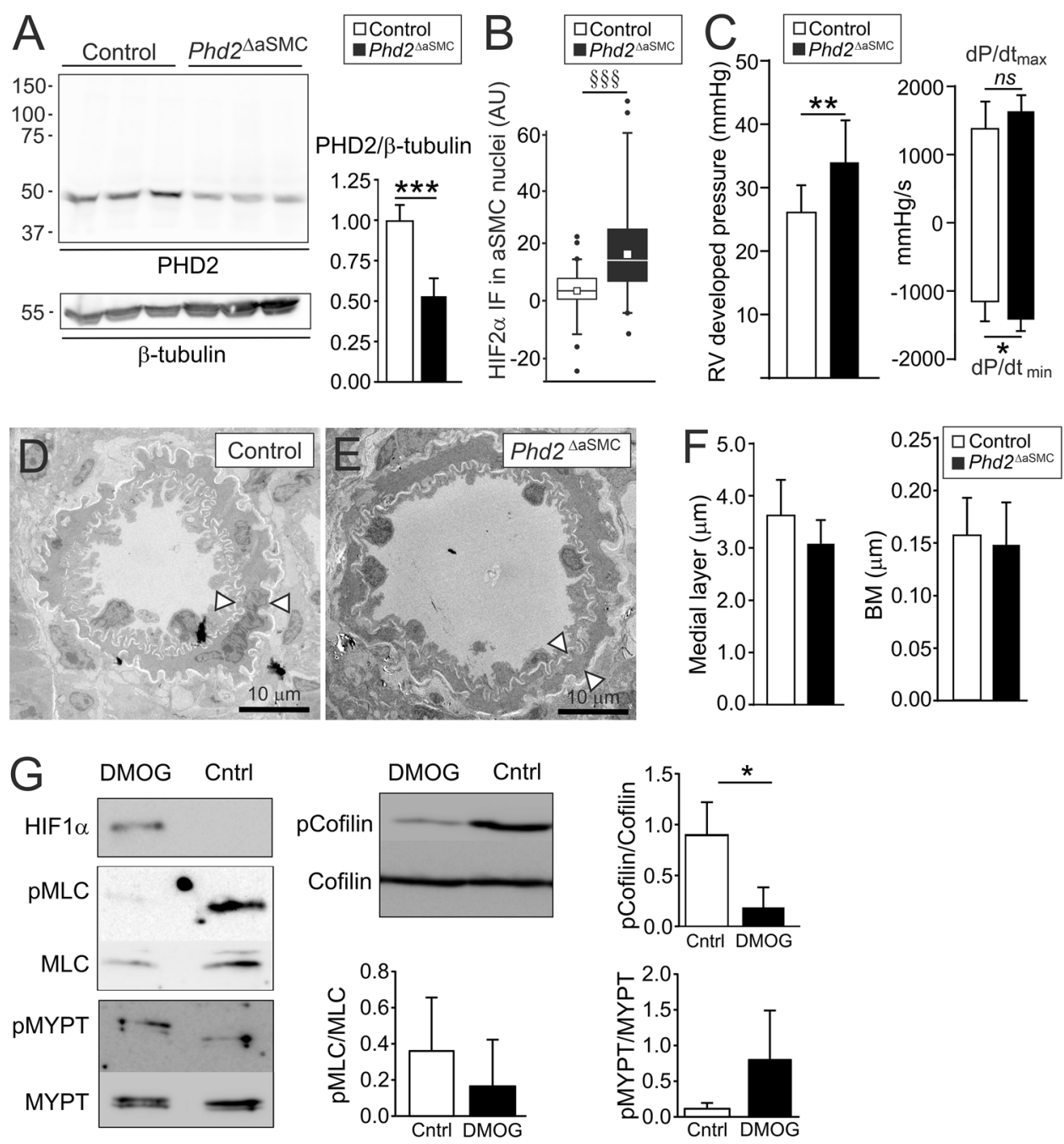

Fig. 7 Phd 2 deletion from arterial smooth muscle cells caused modest pulmonary hypertension in 8-month-old mice without arterial remodeling. A Western blot analysis (scale in $\mathrm{kDa}$ ) of lung lysates showed reduced amount of PHD2 protein in $P h d 2^{\Delta \text { aSMC }}$ mice. Residual PHD2 is expected from Cre-negative cells. Signal intensities quantified on the right, control set to $1, n=6$ mice/genotype. B, Relative HIF $2 \alpha$ immunofluorescence intensity in aSMC nuclei, $n=67$ and 58 aSMC nuclei from three control and three $P h d 2^{\Delta \mathrm{aSMC}}$ mice. Median (line), average (square), 75th quartile (box), 5th and 95th per-

deletion of $P h d 2$. BM remodeling and fibrotic changes could develop as a response to increased hemodynamic stress [49, 50] and EC to stromal cell signaling. In the latter mechanism upregulated ET-1 plays an important role as it induces hypertension, myofibroblast differentiation and fibrosis [42, 51]. Among the known vasoconstrictor agents ET-1 was consistently upregulated in $P h d 2^{\Delta \mathrm{ECi}}$ mice from the earliest age group analyzed and also in ECs after one week of culture in low oxygen environment, which indicates an early role for ET-1 in pulmonary pathologies due to chronic activation of PHD2/HIF signaling. centile (whiskers), outliers $(\bullet)$. C, RV developed pressure and rate of RV pressure development. D-F No differences in the thicknesses of the medial layer of pulmonary arteries $(n=4-5$ mice/genotype) or alveolar capillary BM ( $n=3-6$ mice/genotype) between control and $P h d 2^{\Delta \mathrm{aSMC}}$ mice. G Western blot analysis of phosphorylation levels of proteins indicated from cultured aSMCs treated with PHD inhibitor DMOG or DMSO (control), $n=3$ independent experiments. Mean \pm SD. $* * * P<0.001, * * P<0.01, * P<0.05$ in $t$-test. ${ }^{\S \S} P<0.001$ in Mann-Whitney test

Studies aimed to investigate the pathophysiology of PAH have thus far mainly focused on large vessels while the potential involvement of pulmonary microvasculature has been overlooked. Our ultrastructural analysis of $P h d 2^{\Delta \mathrm{ECi}}$ mice revealed thickening of the respiratory membrane, a two-cell layer formed by alveolar epithelial cells and capillary ECs separated by Col IV, the expression of which was increased in $P h d 2^{\Delta \mathrm{ECi}}$ mice and in ECs cultured in low oxygen. The rate of gas exchange through this specialized BM layer is inversely proportional to its thickness [52] and the observed alterations likely exacerbate respiratory symptoms. This assumption is in line with clinical studies revealing 


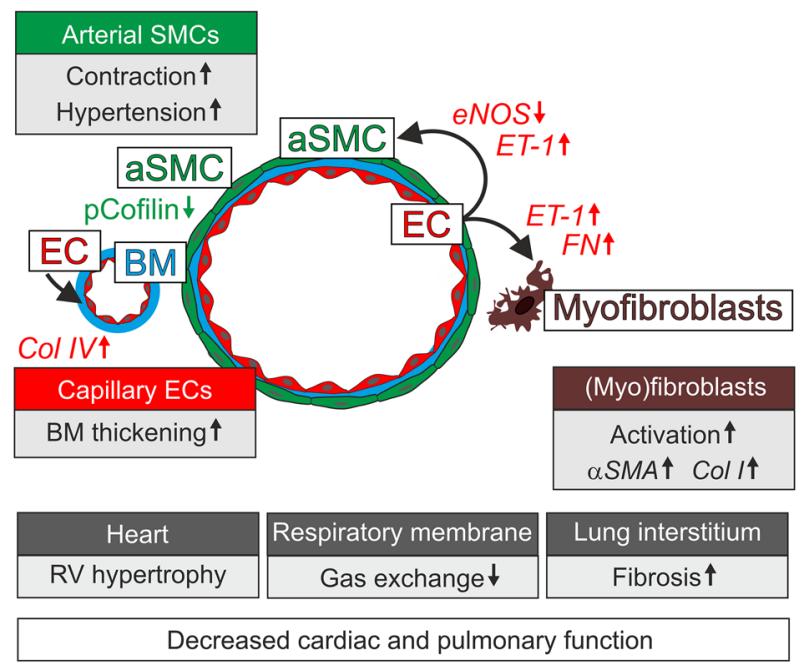

Fig. 8 PHD2-dependent mechanisms in pulmonary hypertension and fibrosis. In ECs PHD2 deficiency results in HIF stabilization and dysregulated expression of vascular tone regulators (eNOS, ET-1) causing hypercontraction of aSMCs and pulmonary hypertension. RV hypertrophy develops secondary to the chronic pressure overload. PHD2 deletion resulted in increased expression of Col IV in ECs and thickened respiratory membrane. In contrast to ECs, in aSMCs PHD2 deletion elevated RV pressure via activated cofilin/actin polymerization without changes in vascular tone regulators. EC produced ET-1 may also promote myofibroblast activation and fibrosis

reduced pulmonary membrane diffusion capacity in the patients with elevated pulmonary arterial pressure indicating functional impairment of the alveolocapillary membrane [53]. Hypertension imposes hemodynamic stress on the alveolar wall, which has been shown to associate with remodeling of the BM [50,54]. In ECs grown in a normoxic atmosphere, we also found upregulation of Col IV following $20 \%$ pulsatile stretching mimicking pathological hypertension $[55,56]$. This suggests that respiratory membrane thickening is likely a net result of EC hypoxia sensing and hypertension induced wall stress in alveoli. This causality can be deduced from the law of LaPlace, which states the inverse relationship of wall stress to wall thickness and has been evidenced in clinical and experimental models [33, 54, 57].

In addition to the animal models discussed above, chronic HIF activation due to a loss-of-function mutation in PHD2 [58], a hypomorphic mutation in HIF-binding von HippelLindau protein (leading to HIF stabilization) $[59,60]$ and a gain of function mutation in HIF2 $\alpha$ [61] are associated with cardiopulmonary pathologies. Furthermore, ECs in the plexiform lesions of PAH patients showed increased HIF levels in situ and in vitro [62, 63]. Identification of the role of PHD2 in the matured vasculature in $P h d 2^{\Delta \mathrm{ECi}}$ mice is not only necessary for better understanding of pathogenesis of pulmonary vasculopathies, but also important to predict possible long-term side effects of PHD2 inhibitors that have recently entered the clinics for anemia treatment [20, 64]. In this respect it is interesting to note that in contrast to severe PAH phenotypes, as one might expect based on previous results [6-8], pulmonary and cardiac complications typical for PAH have been reported only in one patient thus far [65]. While our $P h d 2^{\Delta \mathrm{ECi}}$ model did not recapitulate all PAH pathologies, we did observe progressive vascular resistance and lung damage in aged mice. Based on our results, longterm clinical follow-up would be important to fully evaluate the safety of prolyl hydroxylase inhibitors.

\section{Material and methods}

Generation of the $P h d 2^{\text {loxP }}$ allele is described in Rosendahl et al., (Rosendahl A-H, Raasakka M, Laitala A, Railo A, Miinalainen I, Heljasvaara R, Mäki JM, Myllyharju J, manuscript in preparation). Chd $5^{\mathrm{CreERT} 2}$ mice were kindly provided by Ralf Adams, Max Planck Institute for Molecular Biomedicine, Department of Tissue Morphogenesis, Muenster, Germany and are described previously [22]. $P h d 2^{\operatorname{loxP}}$ and $C h d 5^{\mathrm{CreERT} 2}$ mouse lines were crossed to generate the $C h d 5^{\text {CreERT2}}$; Phd $2^{\text {loxP/loxP }}$ line. $C h d 5^{\text {CreERT2 }}$; $P h d 2^{\text {loxP/loxP }}$ mice were administered with four to five injections of tamoxifen (4-5 mg, T5648, Sigma-Aldrich) intraperitoneally or oral gavage starting from one month of age to generate $P h d 2^{\triangle \mathrm{ECi}}$. Litter mates $C h d 5^{\mathrm{CreERT} 2}$; $P h d 2^{+/+}$, Chd $5^{\mathrm{CrERTT} 2} ; \mathrm{Phd} 2^{+/-}$, or $C h d 5^{\mathrm{CreERT} 2} ; \mathrm{Phd} 2^{\mathrm{lox} / /+}$ received the same tamoxifen administrations and were controls for $P h d 2^{\Delta \mathrm{ECi}}$ mice. No alteration was observed in mice having at least one PHD2 wild type allele $\left(P h d 2^{+}\right)$as also previously noted [66]. RVs were analyzed by echocardiography and the mice euthanized at the age of 3, 6 and 10 months to collect tissue samples. To confirm the efficiency and cell type specificity of the Cre/loxP recombination $\mathrm{Chd5} 5^{\mathrm{CreERT} 2}$; Rosa $26^{\mathrm{mTmG}}$ Cre-reporter mice [67] were treated with the same tamoxifen dosage as above and GFP expression was investigated by confocal microscopy as an indication for Cre/ loxP mediated recombination from tissues of 10-month-old mice. To achieve aSMCs specific $P h d 2$ deletion in the lungs, a floxed $P h d 2$ allele was crossed with an Angpt $4^{\mathrm{Cre}}$ mouse line [34] to generate $P h d 2^{\Delta \mathrm{aSMC}}\left(\right.$ Angpt $4^{\mathrm{Cre} /+} ; P h d 2^{\mathrm{loxP} / \text { loxP }}$ ). To confirm efficiency and cell type specificity of the Cre/ loxP recombination Angpt $4^{\text {Cre }}$ were crossed with Rosa$26^{\mathrm{mTmG}}$ mice. Angpt $4^{\mathrm{Cre}} ; \mathrm{Phd} 2^{\text {loxP/loxP }} \mathrm{RVs}$ were analyzed by echocardiography and the mice euthanized at the age of 8 months to collect tissue samples as described below. In gravimetric analysis tissue weight was normalized with the body weight and presented using the formula; tissue weight/ bodyweight $\times 100$. 


\section{Histological analysis}

Tissue samples were fixed overnight in $10 \%$ formalin or $4 \%$ paraformaldehyde. Fixed tissues were embedded in paraffin, processed and stained with hematoxylin and eosin and Masson's trichrome by routine methods. Myofibroblasts and SMCs were visualized using Cy3- $\alpha$ SMA (C6198, SigmaAldrich) antibody, ECs with endomucin (sc-65495, Santa Cruz Biotechnology). Ki-67 was used as an immunohistochemical marker for cell proliferation (TEC-3, M7249, Dako). Fluorescently labelled sections were imaged using confocal microscopy: Olympus FluoView 1000 UPLSAPO $20 \times / 0.75$ or UPLSAPO $60 \times / 1.35$ oil objectives or with Leica SP8 Falcon by using HC PL APO 63×/1.40 OIL CS2 objective or with Zeiss LSM 780 by using Plan-Apochromat $20 \times / 0.8$ or i Plan-Apochromat $63 \times / 1.4$ oil objectives. Nuclear HIF2 $\alpha$ was quantified from frozen lung sections stained with HIF2 $\alpha$ (\#109616, Abcam) antibody. In this assay, arteries were identified from the tissue sections based on their morphology and $\alpha$ SMA staining. Arterial SMCs and EC nuclei were manually segmented based on DAPI staining and their mean fluorescence intensity was measured using Fiji processing package of Image $\mathrm{J} 2$ software. To correct for technical variations in staining intensities between the slides the mean fluorescence intensity of non-relevant nuclei was subtracted from the nucleus of interest. Histological sections were imaged using Leica DM LB with C Plan $4 \times / 0.1$ objective and Leica DCF320 camera or Zeiss Axio Imager. M2m by using EC Plan-Neofluar $40 \times / 0.75$ objective and Zeiss Axiocam 506 color camera. $\alpha$ SMA positive cells were quantified by analyzing relative intensity of $\alpha$ SMA. In cell culture, HIF $2 \alpha$ nuclear localization was quantified by measuring mean immunofluorescent intensity (\#109616, Abcam). To correct for technical variations in staining intensities between the samples, mean intensity measured from cytoplasm was subtracted from the mean intensity measured from the nucleus. Intensity analyses were done using Fiji.

\section{Western blot analysis}

Lung tissue samples from mice were homogenized in RIPA lysis buffer supplemented with protease inhibitor cocktail (P8340, Sigma-Aldrich). Western blot analysis was performed using anti-PHD2 (NB100-2219 Novus Biologicals and \#4835S Cell Signaling), HIF1 $\alpha$ (NB100-479 Novus Biologicals) and HIF2 $\alpha$ (NB100-122 Novus Biologicals) antibodies. Anti- $\beta$-actin (A2066 Sigma-Aldrich) and anti- $\beta$-tubulin antibodies (Sigma T4026) were used as a loading control. Phospho-MYPT1 (Thr696, 5163T), MYPT1 (2634T), phospho-myosin light chain 2 (Thr18/ Ser19, 3674T), myosin light chain 2 (D18E2, 8505), phospho-Cofilin (Ser3, 77G2) and Cofilin (D3F9, XP® 5175T) antibodies were all from Cell Signaling Technology.

\section{Transmission electron microscopy (TEM)}

Specimens were fixed in $1 \%$ glutaraldehyde and $4 \%$ formaldehyde in $0.1 \mathrm{M}$ phosphate buffer, $\mathrm{pH} 7.4$, then postfixed in $1 \%$ osmium tetroxide, dehydrated in acetone and embedded in Epon LX112 (Ladd Research Industries). $150 \mathrm{~nm}$ sections were stained with toluidine blue to select regions of interest. $80 \mathrm{~nm}$ sections were cut with a Leica Ultracut UCT microtome and imaged using Tecnai Spirit transmission electron microscope (Fei Europe) and Quemesa CCD camera (Olympus Soft Imaging Solutions GMBH).

\section{Morphometrical analysis of pulmonary vasculature}

Arterial wall thickness measurements were performed from TEM micrographs at a $\times 480$ magnification. Medial layer thickness was measured from eight locations to cover the whole circumference of an artery. Internal and external elastic laminae measurements were taken from 13 to 21 locations per artery. Number of SMCs/perimeter of arteries was counted by measuring perimeter based on internal elastic lamina. Capillary BM thickness was determined from at least 20 images (magnification $\times 2900$ ) captured randomly throughout the lung tissue section. The measurements were taken from four locations covering the whole circumference of a capillary. All measurements were averaged to present a single value per artery or capillary. Type II pneumocytes were counted from $3908 \mu \mathrm{m}^{2}$ TEM micrographs (magnification $\times 690$ ) based on their morphological characteristics and normalized to total tissue area by using thresholding-based segmentation in Fiji.

\section{Quantitative RT-PCR}

Total RNA was extracted using an RNeasy Mini or Fibrous Tissue Mini kit (Qiagen) following the manufacturer's protocols. For cDNA synthesis, 1 to $3 \mu \mathrm{g}$ of RNA was mixed with random hexamers and oligo-dT, $200 \mathrm{U}$ M-MLV Reverse Transcriptase (Promega), 20 U RiboLock RNase inhibitor (Thermo Scientific), $0.5 \mathrm{mM}$ dNTP and reaction buffer (50 mM Tris- $\mathrm{HCl}, 75 \mathrm{mM} \mathrm{KCl}, 3 \mathrm{mM} \mathrm{MgCl} 2$ ), incubated at $+42{ }^{\circ} \mathrm{C}$ for $1 \mathrm{~h}$, then at $+70{ }^{\circ} \mathrm{C}$ for $15 \mathrm{~min}$ and diluted $1: 3$ to $1: 10$ in sterile $\mathrm{H}_{2} \mathrm{O}$ and used in qPCR ( $2 \mu \mathrm{l} /$ reaction). Real-time qPCR was performed using a Stratagene $\mathrm{mx} 3005 \mathrm{P}$ qPCR instrument (Agilent Technologies) and Brilliant UltraFast SYBR QPCR Master mix (Agilent Technologies). DNA primer sequences are indicated in the Supplemental Table I.

\section{Right ventricular pressure measurements and echocardiography}

A Vevo 2100 (Fujifilm-Visualsonics) was used to acquire echocardiographic parameters with MS-550D transducer 
(40 MHz, $40 \mu \mathrm{m}$ axial, $90 \mu \mathrm{m}$ lateral resolution) under isoflurane anesthesia (4\% for induction and 1,5\% for maintenance). B-mode, M-mode and Doppler imaging were used to obtain RV size and function as well as aortic and pulmonary flow. All analyses were performed by an experienced sonographer who was blinded for the experimental groups. For open chest RV pressure measurements, the animals were anesthetized with ketamine and xylazine $(112.5 \mathrm{mg} /$ $\mathrm{kg}$ and $15 \mathrm{mg} / \mathrm{kg}$, respectively) and intubated. The chest was cut open with a high temperature cauterizer (Fine Science Tools). A pressure-volume sensor 1.2F (Transonic Science) was introduced into the RV from the apical side. The pressure was recorded and analyzed with Labscribe V2 (iWork Systems inc.). Pressure values were extracted after $5 \mathrm{~min}$ of baseline recording.

\section{Cell culturing}

Human ECs (PromoCell, C0155C) were cultured in Human Endothelial Cell Growth Medium supplemented with growth supplement (Cell Applications), 1\% penicillin/streptomycin (PS) (Sigma-Aldrich) and 10\% FBS (HyClone). Before seeding the cells, the culture plates were coated with Attachment Factor (Cell Applications) for at least $30 \mathrm{~min}$ in $37^{\circ} \mathrm{C}$. For hypoxia experiments, ECs were cultured in $1 \%$ oxygen for 7 days in a hypoxia workstation InVivo400 (Ruskinn). Mouse ECs (C57-6023, Cell Biologics) were cultured in M1168 (Cell Biologics) supplemented with M1168-Kit. Mouse embryonic fibroblasts NIH3T3 (ATCC) were cultured in DMEM-GlutaMAX ${ }^{\mathrm{TM}}-\mathrm{I}$ (Gibco) with $1 \%$ PS and $10 \%$ FBS. Human aSMCs (Cell Applications) were cultured in Smooth Muscle Cell Growth Medium (SMCGM, Cell Applications). To promote maturation to a contractile phenotype the SMCGM was changed to Human SMC Differentiation Medium (Cell Applications) for 5 days. To inhibit the activity of PHD2, the cells were treated with $1 \mathrm{mM}$ or $3 \mathrm{mM}$ of dimethyloxalylglycine, $\mathrm{N}$-(methoxyoxoacetyl)-glycine methyl ester (DMOG, Calbiochem) or $25 \mu \mathrm{M}$ Roxadustat (FG-4592, Cayman Chemicals) for $24 \mathrm{~h}$. Equivalent volume of DMSO was used as a control.

\section{Cell stretching experiments}

Human ECs (PromoCell, C0155C) were cultured until confluence in Col I coated BioFlex plates (Flexcell inc.) and washed two times with culture medium devoid of serum and growth supplement. The cells were exposed to $20 \%$ equibiaxial stretch in $1 \mathrm{~Hz}$ cycles for $24 \mathrm{~h}$ in DMEM supplemented with $0.5 \%$ FBS.

\section{Statistics}

All data is presented as mean \pm standard deviation. Normal distribution and equal variances were tested using the Shapiro-Wilk and $F$-test, respectively. The two-tailed unpaired $t$-test (normally distributed data) and Mann-Whitney test were used for comparison of two groups. In the case of inequal variances Welch's correction was used. Statistical tests were done using Origin Pro software. The test used is indicated in the Figure legends.

Supplementary Information The online version contains supplementary material available at https://doi.org/10.1007/s10456-021-09828-z.

Acknowledgements We thank Jaana Träskelin and Riitta Jokela for excellent technical assistance and Erja Tomperi and Katja Porvari for Ki-67 IHC staining. Biocenter Oulu Transgenic-, Electron Microscopy-, and Light Microscopy Core Facilities and the Oulu Laboratory Animal Center supported by Biocenter Finland and the University of Oulu are acknowledged for their specific scientific expertise and research infrastructure services. Roxadustat was a generous gift from Thomas Kietzmann. Peppi Koivunen is acknowledged for the critical review of the manuscript.

Funding Open Access funding provided by University of Oulu including Oulu University Hospital. Research was supported by the Academy of Finland Centre of Excellence Program (251314) for LE and JM, and the Academy Research Fellow Grant (136880) for LE.

\section{Disclosures}

Conflict of interest JM owns equity in FibroGen Inc., which develops HIF-P4H inhibitors as potential therapeutics. This company supports research in the JM group. All other authors declare no competing financial interests.

Open Access This article is licensed under a Creative Commons Attribution 4.0 International License, which permits use, sharing, adaptation, distribution and reproduction in any medium or format, as long as you give appropriate credit to the original author(s) and the source, provide a link to the Creative Commons licence, and indicate if changes were made. The images or other third party material in this article are included in the article's Creative Commons licence, unless indicated otherwise in a credit line to the material. If material is not included in the article's Creative Commons licence and your intended use is not permitted by statutory regulation or exceeds the permitted use, you will need to obtain permission directly from the copyright holder. To view a copy of this licence, visit http://creativecommons.org/licenses/by/4.0/.

\section{References}

1. Cowburn AS, Crosby A, Macias D, Branco C, Colaço RDDR, Southwood M, Toshner M, Crotty Alexander LE, Morrell NW, Chilvers ER, Johnson RS (2016) HIF2 $\alpha$-arginase axis is essential for the development of pulmonary hypertension. PNAS 113:8801-8806

2. Takeda K, Ho VC, Takeda H, Duan L, Nagy A, Fong G (2006) Placental but not heart defects are associated with elevated hypoxia-inducible factor alpha levels in mice lacking prolyl hydroxylase domain protein 2. Mol Cell Biol 26:8336-8346 
3. Metikala S, Neuhaus H, Hollemann T (2016) Suppression of vascular network formation by chronic hypoxia and prolyl-hydroxylase 2 (phd2) deficiency during vertebrate development. Angiogenesis 19:119-131

4. Takeda K, Cowan A, Fong G (2007) Essential role for prolyl hydroxylase domain protein 2 in oxygen homeostasis of the adult vascular system. Circulation 116:774-781

5. Minamishima YA, Moslehi J, Bardeesy N, Cullen D, Bronson RT, Kaelin WG (2008) Somatic inactivation of the PHD2 prolyl hydroxylase causes polycythemia and congestive heart failure. Blood 111:3236-3244

6. Dai Z, Li M, Wharton J, Zhu MM, Zhao Y (2016) Prolyl-4 Hydroxylase 2 (PHD2) Deficiency in endothelial cells and hematopoietic cells induces obliterative vascular remodeling and severe pulmonary arterial hypertension in mice and humans through hypoxia-inducible factor-2 $\alpha$. Circulation 133:2447-2458

7. Wang S, Zeng H, Chen ST, Zhou L, Xie X, He X, Tao Y, Tuo Q, Deng C, Liao D, Chen J (2017) Ablation of endothelial prolyl hydroxylase domain protein-2 promotes renal vascular remodelling and fibrosis in mice. J Cell Mol Med 21:1967-1978. https:// doi.org/10.1111/jcmm.13117

8. Kapitsinou PP, Rajendran G, Astleford L, Michael M, Schonfeld MP, Fields T, Shay S, French JL, West J, Haase VH (2016) The endothelial prolyl-4-hydroxylase domain 2/hypoxia-inducible factor 2 axis regulates pulmonary artery pressure in mice. Mol Cell Biol 36:1584-1594

9. Alva JA, Zovein AC, Monvoisin A, Murphy T, Salazar A, Harvey NL, Carmeliet P, Iruela-Arispe ML (2006) VE-Cadherin-Crerecombinase transgenic mouse: a tool for lineage analysis and gene deletion in endothelial cells. Dev Dyn 235:759-767

10. Kisanuki YY, Hammer RE, Miyazaki J, Williams SC, Richardson JA, Yanagisawa M (2001) Tie2-Cre transgenic mice: a new model for endothelial cell-lineage analysis in vivo. Dev Biol 230:230-242

11. Zhao Q, Eichten A, Parveen A, Adler C, Huang Y, Wang W, Ding Y, Adler A, Nevins T, Ni M, Wei Y, Thurston G (2018) Singlecell transcriptome analyses reveal endothelial cell heterogeneity in tumors and changes following antiangiogenic treatment. Cancer Res 78:2370-2382

12. Chen Q, Zhang H, Liu Y, Adams S, Eilken H, Stehling M, Corada M, Dejana E, Zhou B, Adams RH (2016) Endothelial cells are progenitors of cardiac pericytes and vascular smooth muscle cells. Nat Commun 7:12422. https://doi.org/10.1038/ncomms12422

13. Chen T, Zhou Q, Tang H, Bozkanat M, Yuan JX, Raj JU, Zhou G (2016) miR-17/20 controls prolyl hydroxylase 2 (PHD2)/hypoxiainducible factor 1 (HIF1) to regulate pulmonary artery smooth muscle cell proliferation. J Am Heart Assoc. https://doi.org/10. 1161/JAHA.116.004510

14. Wirth A, Lemmer B, Greiner E, Lukasova M, Maser-Gluth C, Leutgeb B, Horváth B, Offermanns S, Gorbey S, Gutkind S, Schütz G, Benyó Z, Wettschureck N, Örsy P (2008) Corrigendum: G12-G13-LARG-mediated signaling in vascular smooth muscle is required for salt-induced hypertension. Nat Med 14:222. https:// doi.org/10.1038/nm0208-222

15. Chakraborty R, Saddouk FZ, Carrao AC, Krause DS, Greif DM, Martin KA (2019) Promoters to study vascular smooth muscle. Arterioscler Thromb Vasc Biol 39:603-612

16. Meneses AM, Wielockx B (2016) PHD2: from hypoxia regulation to disease progression. Hypoxia (Auckl) 4:53-67. https://doi.org/ 10.2147/HP.S53576

17. Hölscher M, Silter M, Krull S, von Ahlen M, Hesse A, Schwartz P, Wielockx B, Breier G, Katschinski DM, Zieseniss A (2011) Cardiomyocyte-specific prolyl-4-hydroxylase domain 2 knock out protects from acute myocardial ischemic injury. J Biol Chem 286:11185-11194. https://doi.org/10.1074/jbc.M110.186809
18. Hölscher M, Schäfer K, Krull S, Farhat K, Hesse A, Silter M, Lin Y, Pichler BJ, Thistlethwaite P, El-Armouche A, Maier LS, Katschinski DM, Zieseniss A (2012) Unfavourable consequences of chronic cardiac HIF-1 $\alpha$ stabilization. Cardiovasc Res 94:77-86. https://doi.org/10.1093/cvr/cvs014

19. Kerkelä R, Karsikas S, Szabo Z, Serpi R, Magga J, Gao E, Alitalo K, Anisimov A, Sormunen R, Pietilä I, Vainio L, Koch WJ, Kivirikko KI, Myllyharju J, Koivunen P (2013) Activation of hypoxia response in endothelial cells contributes to ischemic cardioprotection. Mol Cell Biol 33:3321-3329. https://doi.org/10. 1128/MCB.00432-13

20. S D, (2019) Roxadustat: first global approval. Drugs 79:563-572. https://doi.org/10.1007/s40265-019-01077-1

21. Zhao R, Du L, Huang Y, Wu Y, Gunst SJ (2008) Actin depolymerization factor/cofilin activation regulates actin polymerization and tension development in canine tracheal smooth muscle. J Biol Chem 283:36522-36531

22. Wang Y, Nakayama M, Pitulescu ME, Schmidt TS, Bochenek ML, Sakakibara A, Adams S, Davy A, Deutsch U, Lüthi U, Barberis A, Benjamin LE, Mäkinen T, Nobes CD, Adams RH (2010) EphrinB2 controls VEGF-induced angiogenesis and lymphangiogenesis. Nature 465:483-486

23. Kilani B, Gourdou-Latyszenok V, Guy A, Bats M, Peghaire C, Parrens M, Renault M, Duplàa C, Villeval J, Rautou P, Couffinhal $\mathrm{T}$, James C (2019) Comparison of endothelial promoter efficiency and specificity in mice reveals a subset of Pdgfb-positive hematopoietic cells. J Thromb Haemost 17:827-840. https://doi.org/10. $1111 /$ jth. 14417

24. Crapo JD, Barry BE, Gehr P, Bachofen M, Weibel ER (1982) Cell number and cell characteristics of the normal human lung. Am Rev Respir Dis 126:332-337. https://doi.org/10.1164/arrd. 1982.126.2.332

25. Wang S, Zeng H, Xie X, Tao Y, He X, Roman RJ, Aschner JL, Chen J (2016) Loss of prolyl hydroxylase domain protein 2 in vascular endothelium increases pericyte coverage and promotes pulmonary arterial remodeling. Oncotarget 7:58848-58861

26. Galiè N, Hoeper MM, Humbert M, Torbicki A, Vachiery J, Barbera JA, Beghetti M, Corris P, Gaine S, Gibbs JS, GomezSanchez MA, Jondeau G, Klepetko W, Opitz C, Peacock A, Rubin L, Zellweger M, Simonneau G (2009) Guidelines for the diagnosis and treatment of pulmonary hypertension: the Task Force for the Diagnosis and Treatment of Pulmonary Hypertension of the European Society of Cardiology (ESC) and the European Respiratory Society (ERS), endorsed by the International Society of Heart and Lung Transplantation (ISHLT). Eur Heart J 30:2493-2537. https://doi.org/10.1093/eurheartj/ehp297

27. Parasuraman S, Walker S, Loudon BL, Gollop ND, Wilson AM, Lowery C, Frenneaux MP (2016) Assessment of pulmonary artery pressure by echocardiography: a comprehensive review. Int J Cardiol Heart Vasc 12:45-51

28. de Jesus Perez, VA (2016) Molecular pathogenesis and current pathology of pulmonary hypertension. Heart Fail Rev 21:239-257

29. Meyrick B, Reid L (1979) Hypoxia and incorporation of 3H-thymidine by cells of the rat pulmonary arteries and alveolar wall. Am J Pathol 96:51-70

30. Heath D, Williams D, Rios-Dalenz J, Calderon M, Gosney J (1990) Small pulmonary arterial vessels of Aymara Indians from the Bolivian Andes. Histopathology 16:565-571

31. Meyrick B, Reid L (1980) Hypoxia-induced structural changes in the media and adventitia of the rat hilar pulmonary artery and their regression. Am J Pathol 100:151-178

32. Stanley MW, Henry-Stanley MJ, Gajl-Peczalska KJ, Bitterman PB (1992) Hyperplasia of type II pneumocytes in acute lung injury. Cytologic findings of sequential bronchoalveolar lavage. Am J Clin Pathol 97:669-677 
33. Villaschi S, Pietra GG (1986) Alveolo-capillary membrane in primary pulmonary hypertension. Appl Pathol 4:132-137

34. Elamaa H, Kihlström M, Kapiainen E, Kaakinen M, Miinalainen I, Ragauskas S, Cerrada-Gimenez M, Mering S, Nätynki M, Eklund L (2018) Angiopoietin-4-dependent venous maturation and fluid drainage in the peripheral retina. Elife 7:e37776. https://doi.org/ 10.7554/eLife. 37776

35. Anonymous (2018) Single-cell transcriptomics of 20 mouse organs creates a Tabula Muris. Nature 562:367-372. https://doi. org/10.1038/s41586-018-0590-4

36. Touyz RM, Alves-Lopes R, Rios FJ, Camargo LL, Anagnostopoulou A, Arner A, Montezano AC (2018) Vascular smooth muscle contraction in hypertension. Cardiovasc Res 114:529-539

37. Mole DR, Schlemminger I, McNeill LA, Hewitson KS, Pugh CW, Ratcliffe PJ, Schofield CJ (2003) 2-oxoglutarate analogue inhibitors of HIF prolyl hydroxylase. Bioorg Med Chem Lett 13:2677-2680

38. Weise-Cross L, Sands MA, Sheak JR, Broughton BRS, Snow JB, Gonzalez Bosc LV, Jernigan NL, Walker BR, Resta TC (2018) Actin polymerization contributes to enhanced pulmonary vasoconstrictor reactivity after chronic hypoxia. Am J Physiol Heart Circ Physiol 314:H1011-H1021

39. Hales CA (1985) The site and mechanism of oxygen sensing for the pulmonary vessels. Chest $88: 235 \mathrm{~S}-240 \mathrm{~S}$

40. Laitakari A, Huttunen R, Kuvaja P, Hannuksela P, Szabo Z, Heikkilä M, Kerkelä R, Myllyharju J, Dimova EY, Serpi R, Koivunen $P$ (2020) Systemic long-term inactivation of hypoxia-inducible factor prolyl 4-hydroxylase 2 ameliorates aging-induced changes in mice without affecting their life span. FASEB J 34:5590-5609. https://doi.org/10.1096/fj.201902331R

41. Chen Y, Guo H, Xu D, Xu X, Wang H, Hu X, Lu Z, Kwak D, Xu Y, Gunther R, Huo Y, Weir EK (2012) Left ventricular failure produces profound lung remodeling and pulmonary hypertension in mice: heart failure causes severe lung disease. Hypertension 59:1170-1178

42. Rodríguez-Pascual F, Busnadiego O, González-Santamaría J (2014) The profibrotic role of endothelin-1: is the door still open for the treatment of fibrotic diseases? Life Sci 118:156-164

43. Fagan KA, Fouty BW, Tyler RC, Morris KG, Hepler LK, Sato K, LeCras TD, Abman SH, Weinberger HD, Huang PL, McMurtry IF, Rodman DM (1999) The pulmonary circulation of homozygous or heterozygous eNOS-null mice is hyperresponsive to mild hypoxia. J Clin Invest 103:291-299. https://doi.org/10.1172/JCI38 62

44. Fagan KA, Morrissey B, Fouty BW, Sato K, Harral JW, Morris KG, Hoedt-Miller M, Vidmar S, McMurtry IF, Rodman DM (2001) Upregulation of nitric oxide synthase in mice with severe hypoxia-induced pulmonary hypertension. Respir Res 2:306-313. https://doi.org/10.1186/rr74

45. Tang H, Babicheva A, McDermott KM, Gu Y, Ayon RJ, Song S, Wang Z, Gupta A, Zhou T, Sun X, Dash S, Wang Z, Balistrieri A, Zheng Q, Cordery AG, Desai AA, Rischard F, Khalpey Z, Wang J, Black SM, Garcia JGN, Makino A, Yuan JX (2018) Endothelial HIF- $2 \alpha$ contributes to severe pulmonary hypertension due to endothelial-to-mesenchymal transition. Am J Physiol Lung Cell Mol Physiol 314:L256-L275. https://doi.org/10.1152/ajplung. 00096.2017

46. Barnes EA, Chen C, Sedan O, Cornfield DN (2017) Loss of smooth muscle cell hypoxia inducible factor- $1 \alpha$ underlies increased vascular contractility in pulmonary hypertension. FASEB J 31:650-662

47. Tang DD (2015) Critical role of actin-associated proteins in smooth muscle contraction, cell proliferation, airway hyperresponsiveness and airway remodeling. Respir Res 16:134
48. Gunst SJ, Zhang W (2008) Actin cytoskeletal dynamics in smooth muscle: a new paradigm for the regulation of smooth muscle contraction. Am J Physiol Cell Physiol 295:576

49. Kapanci Y, Burgan S, Pietra GG, Conne B, Gabbiani G (1990) Modulation of actin isoform expression in alveolar myofibroblasts (contractile interstitial cells) during pulmonary hypertension. Am J Pathol 136:881-889

50. Parker JC, Breen EC, West JB (1997) High vascular and airway pressures increase interstitial protein mRNA expression in isolated rat lungs. J Appl Physiol 83:1697-1705

51. Shi-Wen X, Chen Y, Denton CP, Eastwood M, Renzoni EA, Bou-Gharios G, Pearson JD, Dashwood M, du Bois RM, Black CM, Leask A, Abraham DJ (2004) Endothelin-1 promotes myofibroblast induction through the ETA receptor via a rac/phosphoinositide 3-kinase/Akt-dependent pathway and is essential for the enhanced contractile phenotype of fibrotic fibroblasts. Mol Biol Cell 15:2707-2719

52. Anonymous Essentials of medical physiology, Elsevier, ISBN: 978-81-312-1566-1. Elsevier

53. Steenhuis LH, Groen HJ, Koëter GH, van der Mark TW (2000) Diffusion capacity and haemodynamics in primary and chronic thromboembolic pulmonary hypertension. Eur Respir J 16:276281. https://doi.org/10.1034/j.1399-3003.2000.16b15.x

54. Berg JT, Breen EC, Fu Z, Mathieu-Costello O, West JB (1998) Alveolar hypoxia increases gene expression of extracellular matrix proteins and platelet-derived growth factor-B in lung parenchyma. Am J Respir Crit Care Med 158:1920-1928

55. Liu X, Ensenat D, Wang H, Schafer AI, Durante W (2003) Physiologic cyclic stretch inhibits apoptosis in vascular endothelium. FEBS Lett 541:52-56

56. Hurley NE, Schildmeyer LA, Bosworth KA, Sakurai Y, Eskin SG, Hurley LH, McIntire LV (2010) Modulating the functional contributions of c-Myc to the human endothelial cell cyclic strain response. J Vasc Res 47:80-90

57. Kay JM, Edwards FR (1973) Ultrastructure of the alveolar-capillary wall in mitral stenosis. J Pathol 111:239-245

58. Talbot NP, Smith TG, Balanos GM, Dorrington KL, Maxwell PH, Robbins PA (2017) Cardiopulmonary phenotype associated with human PHD2 mutation. Physiol Rep 5:13224. https://doi.org/10. 14814/phy2.13224

59. Bushuev VI, Miasnikova GY, Sergueeva AI, Polyakova LA, Okhotin D, Gaskin PR, Debebe Z, Nekhai S, Castro OL, Prchal JT, Gordeuk VR (2006) Endothelin-1, vascular endothelial growth factor and systolic pulmonary artery pressure in patients with Chuvash polycythemia. Haematologica 91:744-749

60. Smith TG, Brooks JT, Balanos GM, Lappin TR, Layton DM, Leedham DL, Liu C, Maxwell PH, McMullin MF, McNamara CJ, Percy MJ, Pugh CW, Ratcliffe PJ, Talbot NP, Treacy M, Robbins PA (2008) Mutation of the von Hippel-Lindau gene alters human cardiopulmonary physiology. Adv Exp Med Biol 605:51-56. https://doi.org/10.1007/978-0-387-73693-8_9

61. Formenti F, Beer PA, Croft QPP, Dorrington KL, Gale DP, Lappin TRJ, Lucas GS, Maher ER, Maxwell PH, McMullin MF, O'Connor DF, Percy MJ, Pugh CW, Ratcliffe PJ, Smith TG, Talbot NP, Robbins PA (2011) Cardiopulmonary function in two human disorders of the hypoxia-inducible factor (HIF) pathway: von Hippel-Lindau disease and HIF-2alpha gain-of-function mutation. FASEB J 25:2001-2011. https://doi.org/10.1096/fj. 10-177378

62. Tuder RM, Chacon M, Alger L, Wang J, Taraseviciene-Stewart L, Kasahara Y, Cool CD, Bishop AE, Geraci M, Semenza GL, Yacoub M, Polak JM, Voelkel NF (2001) Expression of angiogenesis-related molecules in plexiform lesions in severe pulmonary hypertension: evidence for a process of disordered angiogenesis. J Pathol 195:367-374. https://doi.org/10.1002/path.953 
63. Fijalkowska I, Xu W, Comhair SAA, Janocha AJ, Mavrakis LA, Krishnamachary B, Zhen L, Mao T, Richter A, Erzurum SC, Tuder RM (2010) Hypoxia inducible-factor $1 \alpha$ regulates the metabolic shift of pulmonary hypertensive endothelial cells. Am J Pathol 176:1130-1138. https://doi.org/10.2353/ajpath.2010. 090832

64. Chen N, Hao C, Peng X, Lin H, Yin A, Hao L, Tao Y, Liang X, Liu Z, Xing C, Chen J, Luo L, Zuo L, Liao Y, Liu B, Leong R, Wang C, Liu C, Neff T, Szczech L, Yu KP (2019) Roxadustat for anemia in patients with kidney disease not receiving dialysis. $\mathrm{N}$ Engl J Med 381:1001-1010. https://doi.org/10.1056/NEJMoa1813 599

65. Cygulska K, Wejner-Mik P, Plewka M, Figiel Ł, Chrzanowski Ł, Kasprzak JD (2019) Roxadustat: another drug that causes pulmonary hypertension? Report of first human case. Pol Arch Intern Med 129:344-345. https://doi.org/10.20452/pamw.4445

66. Mazzone M, Dettori D, de Oliveira RL, Loges S, Schmidt T, Jonckx B, Tian Y, Lanahan AA, Pollard P, de Almodovar CR, De
Smet F, Vinckier S, Aragonés J, Debackere K, Luttun A, Wyns S, Jordan B, Pisacane A, Gallez B, Lampugnani MG, Dejana E, Simons M, Ratcliffe P, Maxwell P, Carmeliet P (2009) Heterozygous deficiency of PHD2 restores tumor oxygenation and inhibits metastasis via endothelial normalization. Cell 136:839-851. https://doi.org/10.1016/j.cell.2009.01.020

67. Muzumdar MD, Tasic B, Miyamichi K, Li L, Luo L (2007) A global double-fluorescent Cre reporter mouse. Genesis 45:593-605

Publisher's Note Springer Nature remains neutral with regard to jurisdictional claims in published maps and institutional affiliations. 